\title{
Drought explains variation in the radial growth of white spruce in western Canada
}

Chen, Lei

2017-02-15

Chen , L , Huang , J-G, Stadt, K J, Comeau , P G, Zhai , L, Dawson , A \& Alam , S A 2017 , ' Drought explains variation in the radial growth of white spruce in western Canada ' , Agricultural and Forest Meteorology , vol. 233 , pp. 133-142 . https://doi.org/10.1016/j.agrformet.2016.11.012

http://hdl.handle.net/10138/177968

https://doi.org/10.1016/j.agrformet.2016.11.012

acceptedVersion

Downloaded from Helda, University of Helsinki institutional repository.

This is an electronic reprint of the original article.

This reprint may differ from the original in pagination and typographic detail.

Please cite the original version. 
1 Drought explains variation in the radial growth of white spruce in

2 western Canada

3 Lei Chen ${ }^{1,2}$, Jian-Guo Huang ${ }^{1, *}$, Kenneth J. Stadt ${ }^{3}$, Philip G. Comeau ${ }^{4}$, Lihong Zhai ${ }^{1}$,

4 Andria Dawson ${ }^{5}$, Syed Ashraful Alam ${ }^{1,6}$

$6 \quad{ }^{1}$ Key Laboratory of Vegetation Restoration and Management of Degraded Ecosystems,

7 Provincial Key Laboratory of Applied Botany, South China Botanical Garden, Chinese

8 Academy of Sciences, Guangzhou 510650, China

$9{ }^{2}$ Graduate School of Environmental Science, Hokkaido University, N19W8, Sapporo

10 060-0819, Japan

$11 \quad{ }^{3}$ Forest Management Branch, Sustainable Resource Development, Edmonton, Alberta,

12 Canada

$13{ }^{4}$ Department of Renewable Resources, University of Alberta, Edmonton, Alberta,

14 Canada

$15 \quad{ }^{5}$ Department of Geosciences, University of Arizona, Tucson, Arizona, 85721, USA

$16{ }^{6}$ Department of Physics, P.O. Box 48, FI-00014, University of Helsinki, Finland

$17 *$ Corresponding author: Jian-Guo Huang

18 Tel: +86 20 37264225; Fax: +86 20 37264153; E-mail: huangjg @ scbg.ac.cn

19 


\section{Abstract}

24 Many studies have already addressed the existence of unstable and nonlinear relationships between radial growth of white spruce (Picea glauca) and climate variables in boreal forests along the high latitudes $\left(>60^{\circ} \mathrm{N}\right)$. However, along the midlatitudes, the climate-growth relationship is still poorly understood. In this study, we used a network of ring-width chronologies from 40 white spruce sites along a wide latitudinal gradients from $52^{\circ} \mathrm{N}$ to $58^{\circ} \mathrm{N}$ in Alberta, Canada and attempted to understand the complicated response of tree growth to climatic variables and to identify

31 the main limiting factor for the radial growth of white spruce. We combined the empirical linear statistics with the process-based Vaganov-Shashkin Lite (VS-Lite) model requiring only latitude, month mean temperature, and monthly total precipitation information together to better clarify growth-climate relationship. The linear statistical methods indicated that the previous summer temperature imposed a strong negative impact on the radial growth of white spruce while the precipitation and climate moisture index in prior and current summer both had significant positive effects on the radial growth. Similarly, the VS-Lite model showed that the radial growth of white spruce was limited by soil moisture, and temperature-induced drought is the main limiting factor for the radial growth of white spruce. Furthermore, climate-growth relationship varied along different elevations, latitudes, and growing degree days (GDD $>5^{\circ} \mathrm{C}$ ). The radial growth of white spruce in northern stands is often more strongly limited by temperature-induced drought due to the higher temperature and lower precipitation. As the global climate change is in progress, we suggest that more large-scale and 


\section{(}

continuous investigations are needed to address the spatial variation in growth-climate relationship due to the temperature-induced drought.

Keywords: Boreal forest, drought, radial growth, spatial variation, western Canada, white spruce

(1)

\section{Introduction}

The global surface temperature increased approximately $0.85{ }^{\circ} \mathrm{C}$ from 1880 to 2012 , and the period from 1983 to 2012 is thought to be the warmest 30 -year period of the last 14 centuries in the Northern Hemisphere (IPCC, 2014). It is not well understood how these dramatic changes in climate will affect terrestrial biomes (Ma et al., 2012). The largest of these terrestrial biomes is the boreal forest, which is predominantly distributed across northern Eurasia and North America, and covers 11\% of the earth's land surfaces (Dixon et al., 1994; Lindahl et al., 2007). Climate warming will not only influence the function and structure of these boreal forests but also may affect the frequency and severity of abiotic and biotic feedbacks of boreal forests, including outbreaks of forest insects, droughts and wild fires (Stocks et al., 1998; Volney and Fleming, 2000; Kasischke and Stocks, 2012; Price et al., 2013). Therefore, it is critical to understand the response of boreal tree species to climate warming for better predicting potential changes and monitoring in boreal forest ecosystems.

5 Tree rings provide a high-resolution proxy of climate, and have been successfully used by many studies to reconstruct past climatic change (Mann et al., 2002; Esper et al., 
2002; Cook et al., 2004; D'Arrigo et al., 2006; D'Arrigo et al., 2008), and to better understand the relationship between tree growth and climate (Hughes et al., 2010; Speer, 2010; Fritts, 2001). Traditional statistical calibration methods assume a linear relationship between tree growth and climatic factors that is constant through time (Jones et al., 2009; Tolwinski-Ward et al., 2011). As a result of climate warming over the last few decades, various studies (D'Arrigo et al., 2008; Esper and Frank, 2009; Zhang and Wilmking, 2010; Visser et al., 2010) have considered the existence of unstable and nonlinear relationships between tree growth and climate. In particular, it has been shown that white spruce (Picea glauca (Moench) Voss) has a complex nonlinear response to climate, at least in parts of Alaska and Yukon, Canada (Wilmking et al., 2004; D'Arrigo et al., 2004; Lloyd et al., 2013). For example, many studies have demonstrated a reduction in the sensitivity of the growth of white spruce to temperature in high altitude boreal forests, especially in Alaska and northern Canada (Jacoby and D'Arrigo, 1995; Lloyd and Fastie, 2002; Wilmking et al., 2004; Andreu-Hayles et al., 2011; Porter and Pisaric, 2011; Chavardès et al., 2013; Lloyd et al., 2013), which is referred to as the divergence problem (D'Arrigo et al., 2008). Except for the temporal change in the climate-growth relationship, the response of radial growth to climate variables also varied along latitudinal gradients in boreal forests (Mäkinen et al., 2002; Huang et al., 2010; Lloyd et al., 2011). Therefore, large spatial scale tree-ring study is needed to clearly address how radial growth responds to climatic factors. 
The process-based Vaganov-Shashkin (VS) model that estimates tree-ring growth from environmental inputs has the ability to resolve the non-stationary and nonlinear feature of the climate-growth relationship (Vaganov et al., 2006; Vaganov et al., 2011; Zhang et al., 2011; Touchan et al., 2012). However, the application of the VS model is limited due to its complex structure and required parameter inputs. Tolwinski-Ward et al. (2011) proposed a simplified version of the VS model (VS-Lite), which only requires latitude, monthly temperature and precipitation as inputs. Recent studies have shown that the nonlinear VS-Lite model can capture the growth trajectories of tree-ring series for a variety of environmental conditions and species (Tolwinski-Ward et al., 2011; Breitenmoser et al., 2014). Although the nonlinear response of white spruce growth to climate has been investigated in several high-latitude boreal forests, the climate-growth relationship of white spruce in mid-latitude forests is still poorly understood.

In this study, we used a network of ring-width chronologies from 40 white spruce sites in the boreal forest along mid-latitudinal gradient from $52^{\circ} \mathrm{N}$ to $58^{\circ} \mathrm{N}$ in Alberta, Canada. The objectives of this study were to: (1) clarify the response of the radial growth of white spruce to climate variables by comparing the results of traditional empirical linear function analysis and growth estimates from the VS-Lite model, (2) investigate the potential spatial variability in the radial growth of white spruce along the latitudinal gradient. As the western Canadian boreal forest is sensitive to climate change (Peng et al., 2011), in which elevations, latitudes and site effects could lead to spatial variability in climate change (Gewehr et al., 2014), we hypothesized that impacts 
110 of drought on the radial growth of white spruce could also vary along latitudinal

111 gradients.

112

113

114

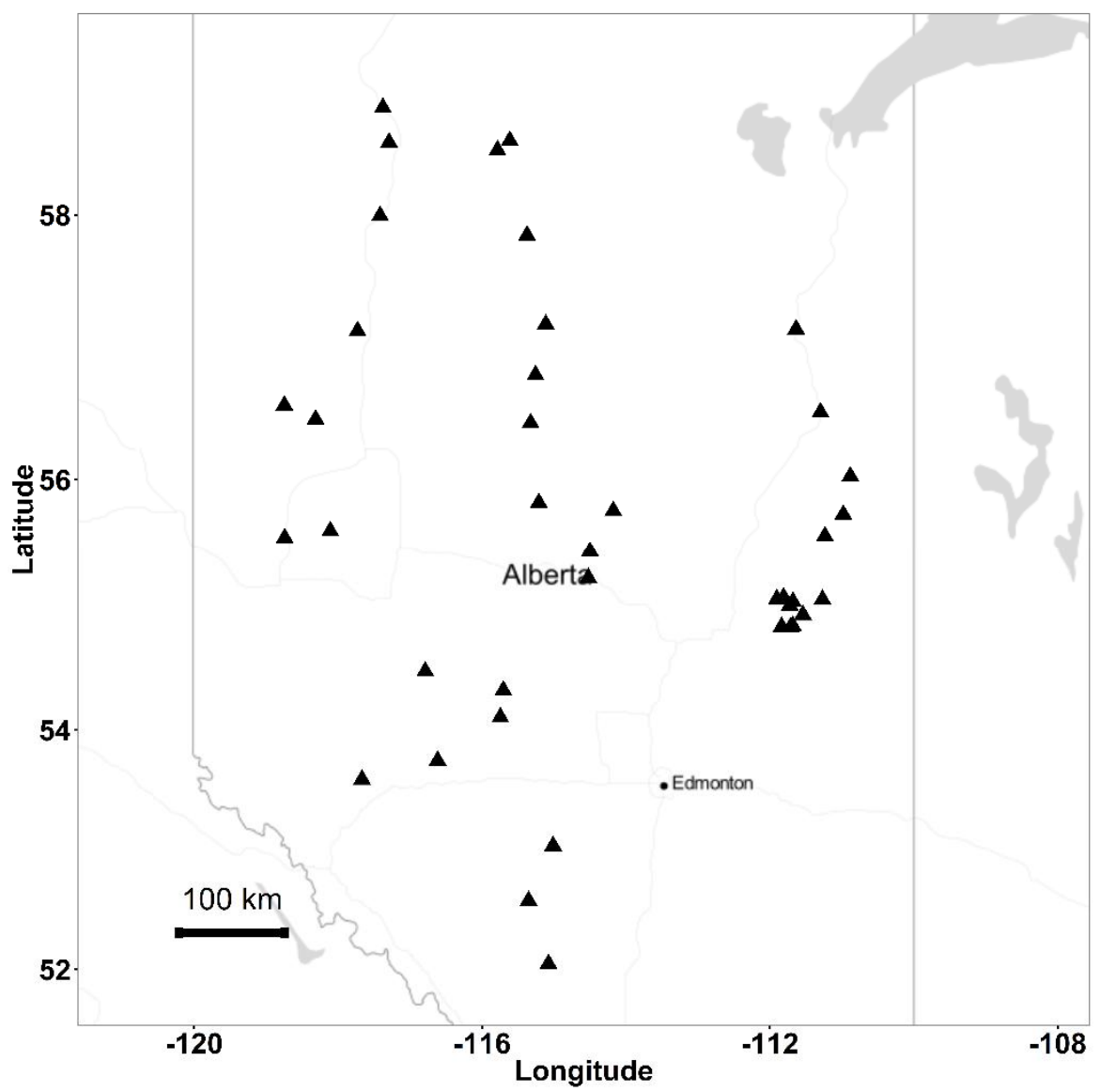

115 Fig. 1 Locations of the study sites (40 white spruce stands).

116

117 2. Materials and methods

$118 \quad 2.1$ Study area

119 The study area is located within the mixedwood forests in Alberta, Canada, which

120 covers $75 \%$ of the forested area in the province. The dominant species in these forests

121 are white spruce, trembling aspen (Populus tremuloides Michx.), balsam poplar 

white spruce. 1996).

[Abies balsamea (L.) Mill.] (Cumming et al., 2000; Stadt et al., 2007). In addition, Lodgepole pine (Pinus contorta Douglas ex Loudon) exists within these mixed forests. Forty sample sites were distributed throughout these regions (Fig. 1), which are under typically dry continental climate conditions. The monthly mean temperature and precipitation from 1930 to 2010 were around $1{ }^{\circ} \mathrm{C}$ and $460 \mathrm{~mm}$, respectively (Appendix S1). The main soil types were brunisols and orthic gray luvisols (Beckingham et al.,

\subsection{Climate data}

The interpolated climate data during the period of $1930-2010$ for all the 40 sites were generated using ANUSPLIN (version 4.3) incorporated thin plate-smoothing splines to develop continuous climate surfaces across space based on the limited observed data (Hutchinson, 2004). In this study, the climate variables used include monthly mean temperature $(T)$, monthly total precipitation, and growing degree days (GDD $>5^{\circ} \mathrm{C}$ ). The climate moisture index (CMI) (Hogg, 1994; Hogg, 1997) has been successfully applied to predict impacts of drought on aspen forests in western Canada (Hogg et al., 2005; Hogg et al., 2008; Michaelian et al., 2011; Hogg et al., 2013). Therefore, the CMI was also calculated to explore the potential effect of drought on the radial growth of 
144 We randomly sampled accessible white spruce dominated mixedwood stands where

145 over $2 / 3$ trees were white spruce, the stand age ranged from 25 to 100 years according

146 to the Phase 3 inventory database (AESRD, 2012). An average of 10 trees were sampled

147 from each site. Trees for tree-ring analyses were either cored or felled. A disk of each

148 sampled tree was collected from stump height $(0.3 \mathrm{~m})$. In addition, two $5.1 \mathrm{~mm}$

149 increment cores were collected at $1.3 \mathrm{~m}$ height from each sampled tree.

150

151 In the laboratory, all tree-ring increment cores were dried and polished with

152 successively finer grits of sandpaper. All tree ring samples were visually crossdated,

153 then measured using a Velmex measuring system with $0.001 \mathrm{~mm}$ resolution. Visual

154 cross-dating was verified using COFECHA (Holmes, 1983). Age- and size-related

155 growth trends were removed by detrending raw tree-ring series using a spline with a

$15650 \%$ frequency response (Cook and Kairiukstis, 1990). Standardized tree-ring series

157 often contain low-frequency variation, such as biological persistence. An

158 autoregressive (AR) model was used to remove the low-frequency persistence and

159 enhance the residual common signal. Residual chronologies were developed using a

160 biweight robust mean to reduce the effect of outliers. The chronology was constructed

161 using the dplR package (Bunn, 2008) of R (R Core Team, 2015). In total, 40 white

162 spruce residual ring-width chronologies were constructed.

163

164 2.4. Climate-growth analysis

165 2.4.1 Traditional statistical analysis 
166 The climate-growth relationship was assessed by comparing climate data to the residual

167 chronologies both in a correlation analysis and with a linear mixed model. Temperature

168 and precipitation from previous May to August of the current growing season were

169 tested. In the correlation analysis, climate variables were correlated with residual

170 chronologies. Bootstrapping was used to test the significance of Pearson's correlation

171 values and increase the reliability. Then the linear regression was used to explore the

172 variation in the correlation coefficients along different elevations, latitudes, and

173 growing degree days $\left(\mathrm{GDD}>5^{\circ} \mathrm{C}\right)$.

174

175 Linear mixed model was used to analyze the effects of climate variables on white spruce

176 growth. The linear mixed model is written as

177

$$
W_{i j}=\beta_{0}+\beta_{1} x_{i j}+\mu_{i 1}+\mu_{i 2} x_{i j}+\varepsilon_{i j}
$$

178 where $W_{i j}$ and $x_{i j}$ represent the ring width of residual chronologies and the climate

179 variables for site $i$ and year $j ; \beta_{0}$ and $\beta_{1}$ are the fixed effects; $\mu_{i 1}$ and $u_{i 2}$ are the

180 random intercept and random slope; $\varepsilon_{i j} \sim N\left(0, \sigma^{2}\right)$ are the errors in the within-site

181 measurement, $\mu_{i 1}, \mu_{i 2}$ and $\varepsilon_{i j}$ are assumed to be independent. Precipitation and

182 temperature were entered into the models as fixed effects, while differences of

183 precipitation and temperature within each site were used as the random slopes. Linear

184 mixed model parameters were estimated using the lme4 package (Bates et al., 2014) of

185 R (R Core Team, 2015). 
Table 1. Parameters of the VS-Lite model

\begin{tabular}{lll}
\hline Temperature response parameters & & Value \\
\hline Threshold temp. for $\mathrm{g}_{\mathrm{T}}>0$ & $\mathrm{~T}_{1}$ & {$\left[1{ }^{\circ} \mathrm{C}, 9^{\circ} \mathrm{C}\right]$} \\
Threshold temp. for $\mathrm{g}_{\mathrm{T}}=1$ & $\mathrm{~T}_{2}$ & {$\left[10^{\circ} \mathrm{C}, 24^{\circ} \mathrm{C}\right]$} \\
Moisture response parameters & & \\
Threshold soil moist. for $\mathrm{g}_{\mathrm{M}}>0$ & $\mathrm{M}_{1}$ & {$[0.01,0.035]$} \\
Threshold soil moist. for $\mathrm{g}_{\mathrm{M}}=1$ & $\mathrm{M}_{2}$ & {$[0.1,0.7]$} \\
Soil moisture parameters & & \\
Runoff parameter 1 & $\alpha$ & $0.093 \mathrm{month}$ \\
Runoff parameter 2 & $\mu$ & 5.8 \\
Runoff parameter 3 & $m$ & 4.886 \\
Max moisture held by soil & $W_{\max }$ & $0.8 \mathrm{v} / \mathrm{v}$ \\
Min moisture held by soil & $W_{\min }$ & $0.01 \mathrm{v} / \mathrm{v}$ \\
Root (bucket) depth & $d_{r}$ & $1000 \mathrm{~mm}$ \\
Integration window parameters & & -4 \\
Integration start month & $I_{0}$ & 12 \\
Integration start month & $I_{f}$ & \\
\hline
\end{tabular}

190 A complete description of the VS-Lite model can be found in the (Tolwinski-Ward et

191 al., 2011). The total radial growth for month $i$ is determined by insolation-related

192 growth $g_{E}$, temperature-related growth $g_{T}$ and soil moisture-related growth $g_{M}$, where

$193 G(i)=g_{E}(i)^{*} \min \left\{g_{T}(i), g_{M}(i)\right\}$

194 Annual growth is calculated by the integrating monthly growth for a calendar year. The

195 parameter $g_{E}(i)$ is the ratio of the mean monthly day length to that in the summer 
197 following formulas:

198

$$
g_{T}(i)=\left\{\begin{array}{ccc}
0 & \text { if } & T_{i} \leq T_{1} \\
\frac{T_{i}-T_{1}}{T_{2}-T_{1}} & \text { if } & T_{1}<T_{i} \leq T_{2} \\
1 & \text { if } & T_{i}>T_{2}
\end{array}\right.
$$

199

$$
g_{M}(i)=\left\{\begin{array}{ccc}
0 & \text { if } & M_{i} \leq M_{1} \\
\frac{M_{i}-M_{1}}{M_{2}-M_{1}} & \text { if } & M 1^{<} M_{i} \leq M_{2} \\
1 & \text { if } & M_{i}>M_{2}
\end{array}\right.
$$

200 where $T_{i}$ and $M_{i}$ are the temperature and soil moisture values for month $i$, and $T_{1}$,

$201 T_{2}, M_{1}$ and $M_{2}$ are user-specified the thresholds of temperatures and soil moistures.

202 The VS-Lite model requires latitude, monthly mean temperature and total precipitation

203 as inputs to simulate the growth of tree-ring width in response to soil moisture and

204 temperature. The fitted results of the VS-Lite model are only sensitive to the four 205 parameters: $T_{1}, T_{2}, M_{1}$ and $M_{2}$, which determine the nonlinear tree-ring growth 206 responds to temperature and moisture. The parameters used here, as listed in Table 1, 207 are the same as those published previously (Tolwinski-Ward et al., 2011; Breitenmoser 208 et al., 2014). A Bayesian estimation method was used for the estimation of parameters 209 of the model (Tolwinski-Ward et al., 2013), The Bayesian estimation method assumes 210 the priors of the parameters $\left(T_{1}, T_{2}, M_{1}\right.$ and $\left.M_{2}\right)$ are uniform distributions and the 211 medians of the posterior distributions are used as the estimated values.

\section{Results}

\subsection{Statistical parameters of the chronologies}


215 Chronology lengths ranged from 28 to 81 years (Appendix S2). The mean \pm SD tree216 ring width of the chronologies was $1.18 \pm 0.76 \mathrm{~mm}$ for all the 40 sites. In addition, both

217 positive and negative values of the skew and the first order autocorrelation existed 218 among the chronologies (Appendix S2).
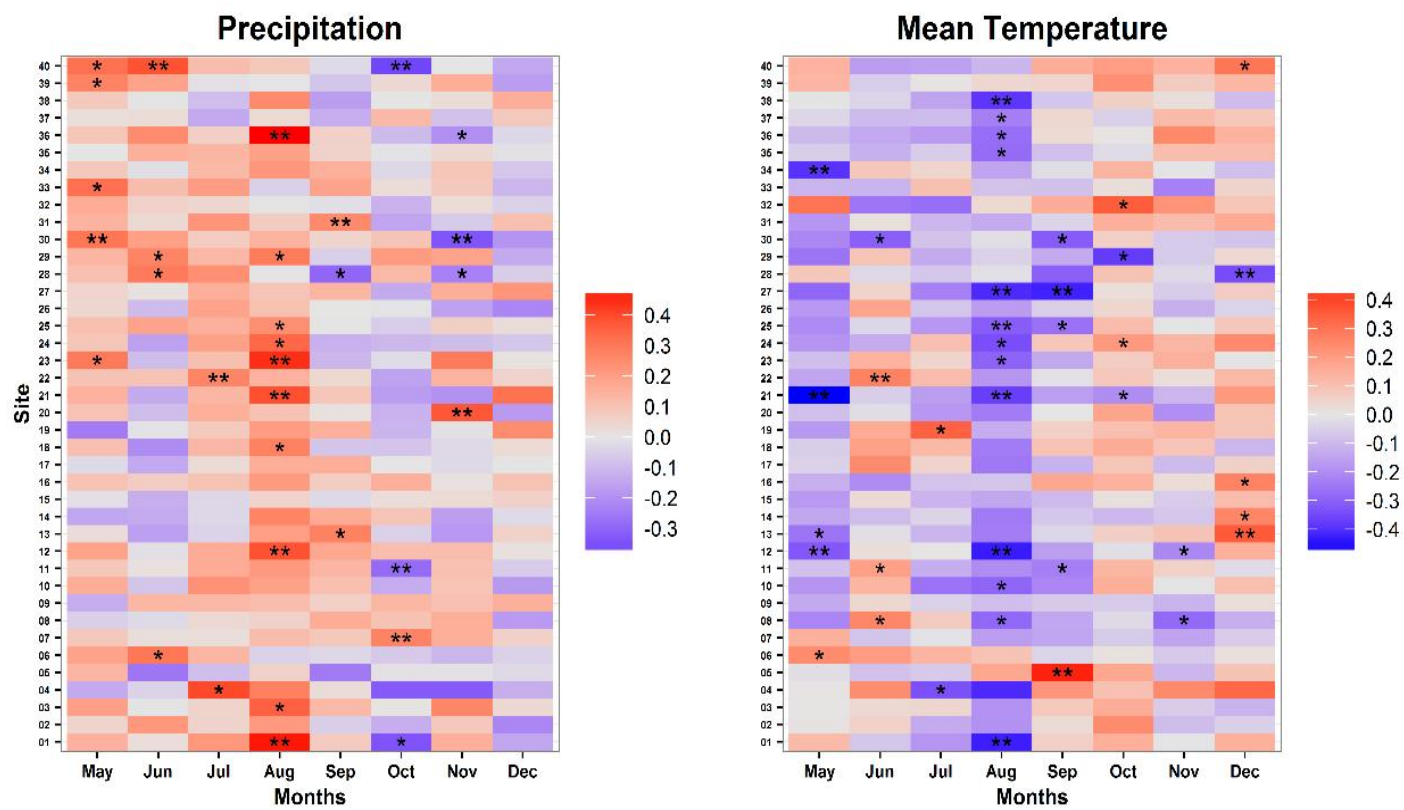

221 Fig. 2 Bootstrapped correlation coefficients of radial growth and the climate

222 variables of the previous year. One asterisk and two asterisks represent $p<0.05, p<0.01$, 223 respectively. 

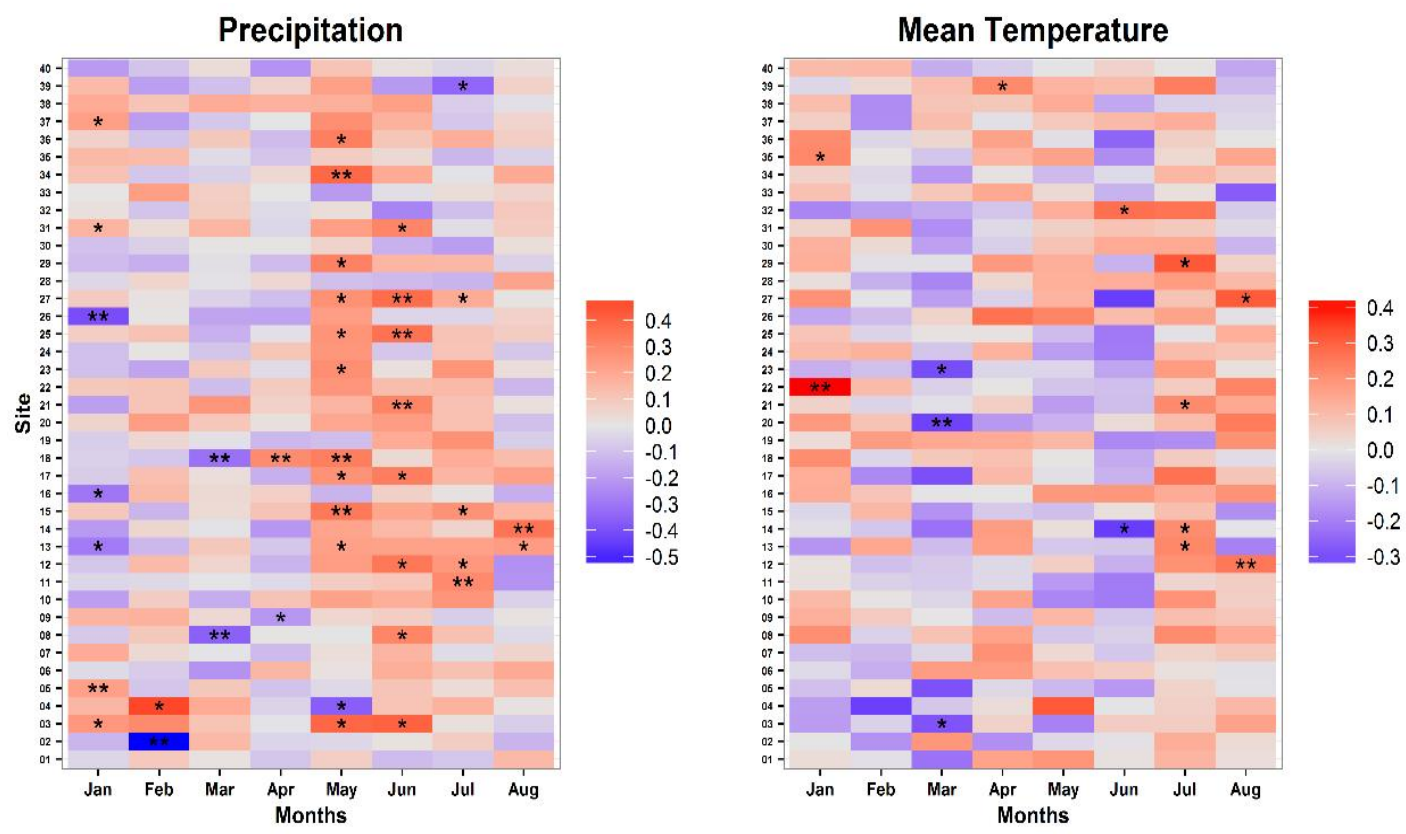

226 Fig. 3 Bootstrapped correlation coefficients of radial growth and the climate

227 variables of the current year. One asterisk and two asterisks represent $p<0.05, p<0.01$, 228 respectively.

\section{$230 \quad 3.2$ Response of tree-ring growth to climate variables}

\section{$231 \quad 3.2 .1$ Correlation analysis}

232 In general, radial growth of white spruce was negatively correlated with summer

233 temperatures of the previous year (Fig. 2). Results indicated that the radial growth in

234 four sites showed significant negative response to the temperature of previous May

235 and the radial growth in 13 sites was significantly negatively correlated with the

236 temperature of previous August (Fig. 2). In contrast, radial growth often positively

237 correlated with the temperature during the period between October and January 238 although only a few significant responses were found (Figs. 2 and 3). In current growing 
season, radial growth often negatively correlated with the mean temperature in July

240 with four significant cases (Fig. 3).

242 The radial growth of white spruce in 10 sites was significantly positively correlated

243 with previous August precipitation (Fig. 2). Then the strong positive response to

244 precipitation gradually declined and even became negative (Fig. 2). From January to

245 April, no clear patterns for the correlations of radial growth and precipitation were

246 observed (Fig. 3). In comparison, radial growth often showed strong positive responses

247 to precipitation of current May and June (Fig. 3). Incidentally, the responses of radial

248 growth to CMI were very similar to precipitation (Appendix S3).

\subsubsection{Linear mixed model}

251 For all 40 sites, precipitation of both previous and current growing season often had a

252 positive effect on the radial growth (Table 2), which was consistent with climate

253 moisture index (see Appendix S4). The temperature of previous summer negatively

254 influences the growth of white spruce, then became positive in winter, followed by 255 negative and positive effect in March and April, respectively (Table 2). In the following 256 season, the effect of temperature on the growth of tree-ring width turned to negative in 257 June again (Table 2). In contrast to the strong negative effects of temperature of 258 previous summer, the growth of white spruce was positively influenced by the temperature of current July (Table 2). 
261 Table 2. Estimates of the linear mixed models for the effect of monthly total 262 precipitation $(P)$, monthly mean temperature $\left(T_{\text {mean }}\right)$ of previous year (from May to 263 Dec) and current year (from Jan to Aug) on the tree-ring width of white spruce. "ns", 264 one asterisk and two asterisks represent $p \geq 0.05, p<0.05$ and $p<0.01$, respectively. 265

\begin{tabular}{ccccccccccc}
\hline Variables & $\begin{array}{c}\text { Previous } \\
\text { year }\end{array}$ & Estimate & SE & $t$ value & Sig. & $\begin{array}{c}\text { Current } \\
\text { year }\end{array}$ & Estimate & SE & $t$ value & Sig. \\
\hline \multirow{2}{*}{$P$} & May & 0.081 & 0.022 & 3.748 & $* *$ & Jan & 0.018 & 0.026 & 0.719 & ns \\
& June & 0.032 & 0.023 & 1.414 & ns & Feb & 0.023 & 0.022 & 1.046 & ns \\
& July & 0.087 & 0.022 & 4.024 & $* *$ & Mar & -0.002 & 0.022 & -0.100 & ns \\
& Aug & 0.173 & 0.022 & 7.812 & $* *$ & Apr & -0.017 & 0.022 & -0.774 & ns \\
& Sep & 0.044 & 0.022 & 2.024 & $*$ & May & 0.150 & 0.026 & 5.740 & $* *$ \\
& Oct & -0.028 & 0.024 & -1.161 & ns & Jun & 0.135 & 0.022 & 6.011 & $* *$ \\
& Nov & 0.023 & 0.024 & 0.956 & ns & Jul & 0.061 & 0.022 & 2.846 & $* *$ \\
& Dec & -0.001 & 0.022 & -0.032 & ns & Aug & 0.041 & 0.022 & 1.885 & ns \\
& May & -0.090 & 0.023 & -3.871 & $* *$ & Jan & 0.060 & 0.022 & 2.800 & $* *$ \\
& June & -0.005 & 0.022 & -0.248 & ns & Feb & -0.006 & 0.022 & -0.298 & ns \\
& July & -0.049 & 0.022 & -2.240 & $*$ & Mar & -0.042 & 0.022 & -1.970 & $*$ \\
& Aug & -0.172 & 0.022 & -7.840 & $* *$ & Apr & 0.050 & 0.022 & 2.342 & $*$ \\
& Sep & -0.048 & 0.022 & -2.118 & $*$ & May & 0.021 & 0.022 & 0.955 & ns \\
& Oct & 0.055 & 0.022 & 2.522 & $*$ & Jun & -0.049 & 0.022 & -2.265 & $*$ \\
& Nov & 0.003 & 0.022 & 0.153 & ns & Jul & 0.078 & 0.021 & 3.622 & $* *$ \\
& Dec & 0.063 & 0.022 & 2.911 & $* *$ & Aug & 0.037 & 0.022 & 1.735 & ns \\
\hline
\end{tabular}

266

267

$268 \quad 3.2 .3$ VS-Lite model

269 A correlation analysis between the VS-Lite estimated chronologies and the true

270 chronologies found that 30 out of 40 sites were significantly correlated (mean $r=0.33$,

$271 \mathrm{SD}=0.11$ ) (Appendix S5). The simulated values of the temperature-induced growth $g_{T}$

272 was generally zero in cold winter, followed by a gradually increasing and peaked in

273 summer (Fig. 4). The soil moisture-related growth curve $g_{M}$ was affected by both

274 precipitation and temperature. The pointwise minimum of the simulated $g_{T}$ and $g_{M}$ 

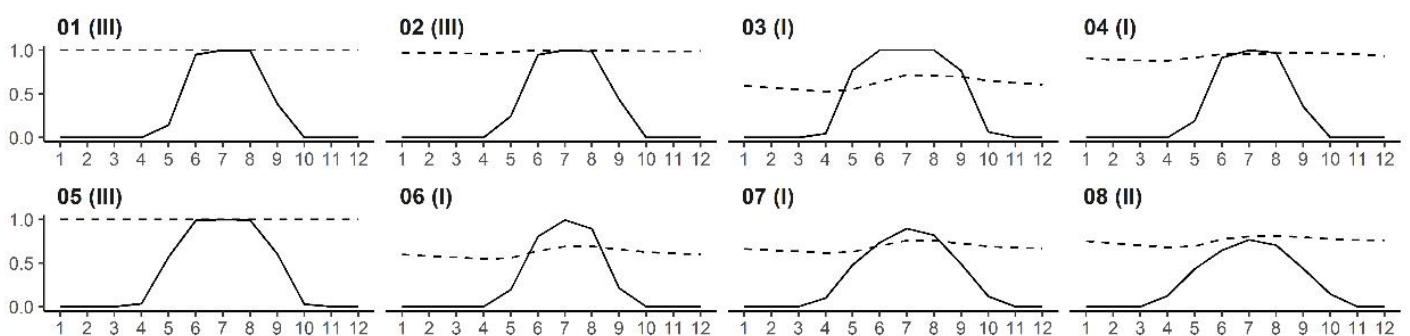

06 (I)

07 (I)

08 (II)
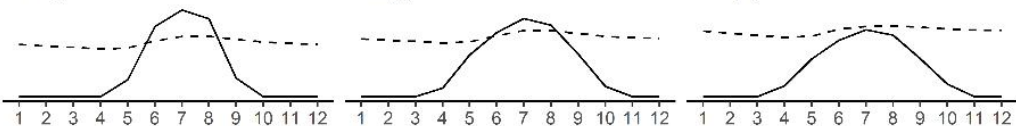

09 (I)

10 (I)

11 (I)

12 (I)
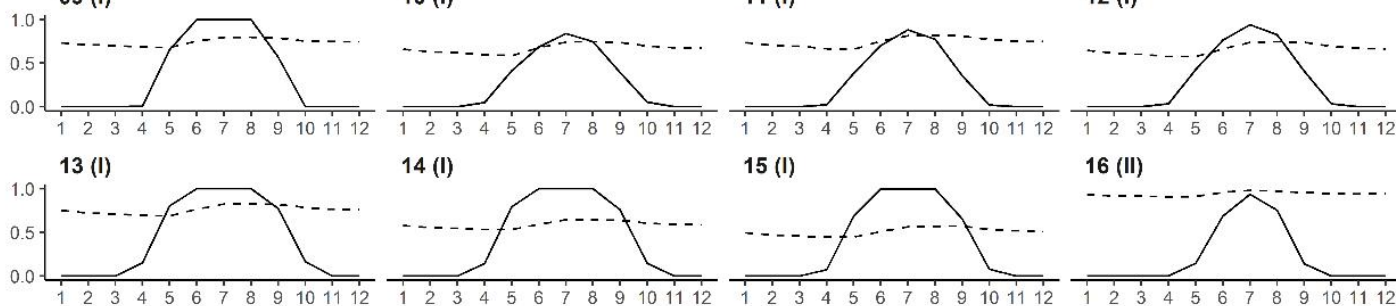

14 (I)

15 (I)

16 (II)
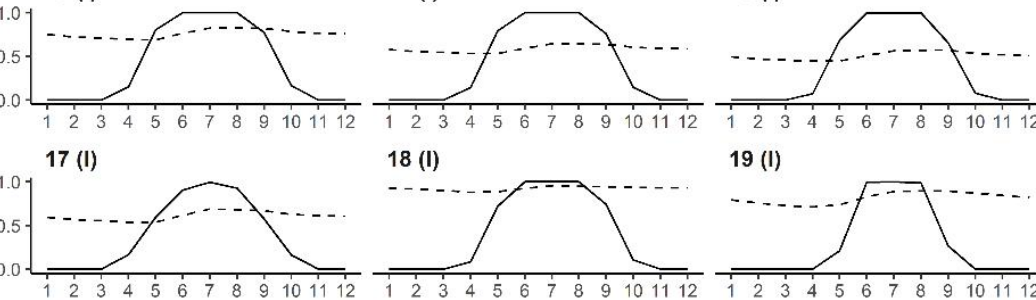

18 (I)

19 (I)
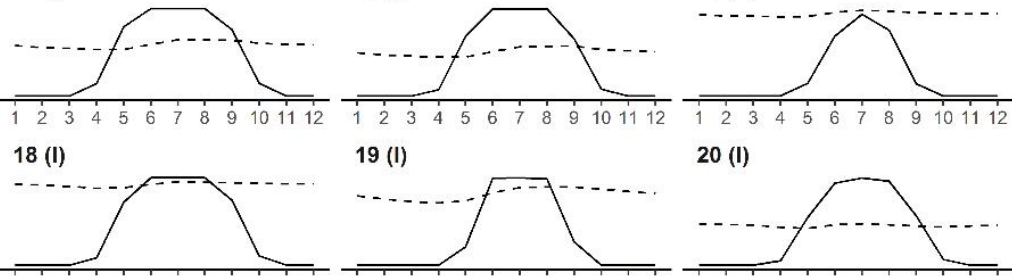

19 (I)

20 (I)

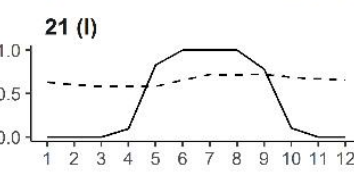

22 (I)
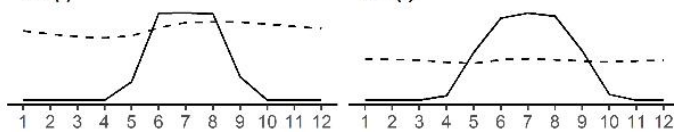

23

24 (I)

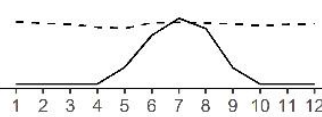

23 (I)
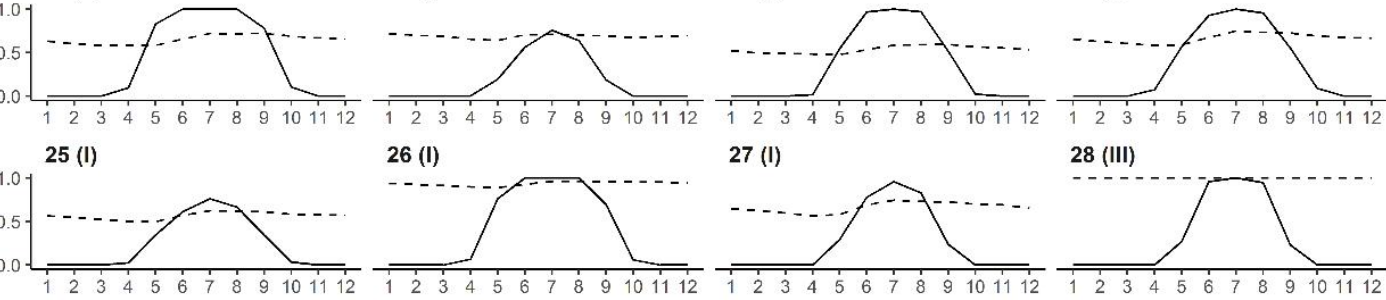

26 (I)

27 (I)

28 (III)
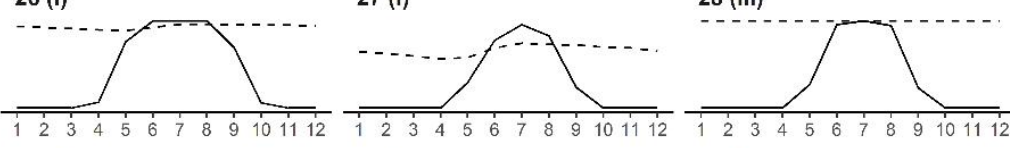

29 (I)

30 (II)

31 (I)

32 (II)
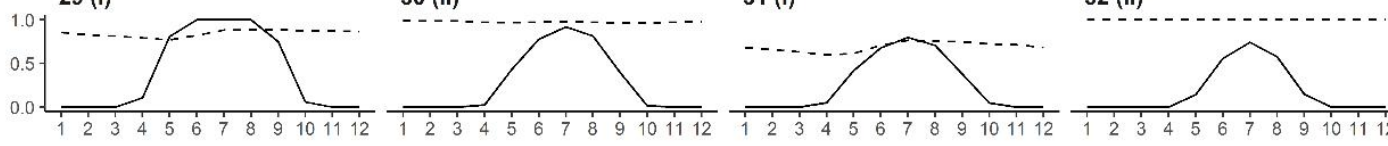

33 (III)

34 (I)

35 (III)
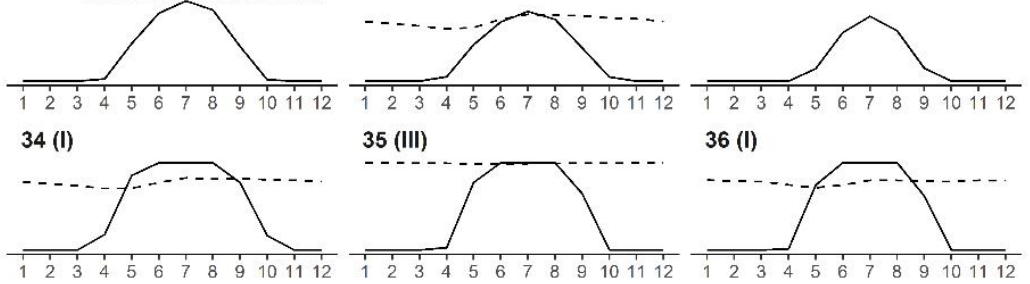

36 (I)
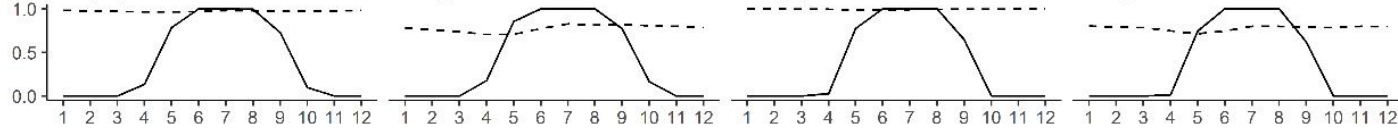

39 (III)

40 (III)

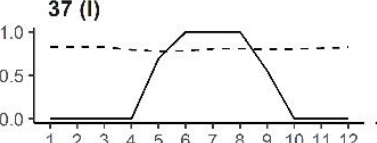

38 (I)

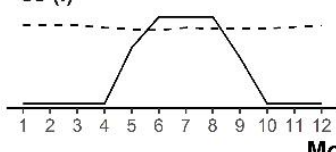

Month

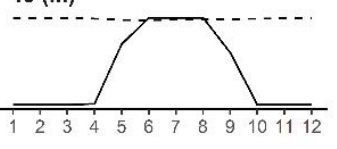

Fig. 4 Simulated growth response curves of temperature and soil moistures. The

278 solid and dashed lines represent the response curves of temperature and soil moisture,

279 respectively. The labels I (moisture limited), II (temperature limited) and III (neither limited by temperature nor moisture) show the growth pattern of each site. 
282 curves determines which variable is limiting in any given month. According to the 283 modeled temperature and soil moisture growth response curves $g_{T}$ and $g_{M}$ (Fig. 4), the 284 forty radial growth patterns can be divided into three groups: pattern I, moisture limited; 285 pattern II, temperature limited; and pattern III, neither limited by temperature nor 286 moisture. The correlations of the averaged observed and simulated chronologies for the 287 three patterns were all significant, which were $0.465,0.296$, and 0.566 , respectively 288 (Appendix S6). For example, the radial growth in sites 3 and 6 was mainly limited by 289 moisture while it was limited by temperature for the radial growth in site 8 (Fig. 4). In 290 comparison, the simulated values of $g_{T}$ and $g_{M}$, from June to August, were similar for 291 the radial growth in sites 1, 2 and 5, and were therefore classified as pattern III (Fig. 4). 292 In total, the radial growth in 28 sites was limited by moisture while the temperature 293 limited ones were only found in four sites (site 08, 16, 30, 32; Fig. 4). There were eight 294 sites where the pattern III was found due to similar simulated values of $g_{T}$ and $g_{M}$ in 295 summer (Fig. 4). The results indicated that the growth of white spruce was most often 296 limited by soil moisture as opposed to temperature and varied spatially.

3.3 Difference of the growth-climate relationship along different elevations,

299 latitudes, and growing degree days (GDD $\left.>5^{\circ} \mathrm{C}\right)$

300 The results of VS-Lite model showed, in total, the radial growth in 28 sites was limited 301 by soil moisture, which distributed extensively from $53.05^{\circ} \mathrm{N}$ to $58.53^{\circ}$ (Fig. 4 , 302 Appendix S2). The four sites with pattern II located from $54.48^{\circ} \mathrm{N}$ to $57.15^{\circ} \mathrm{N}$. In 

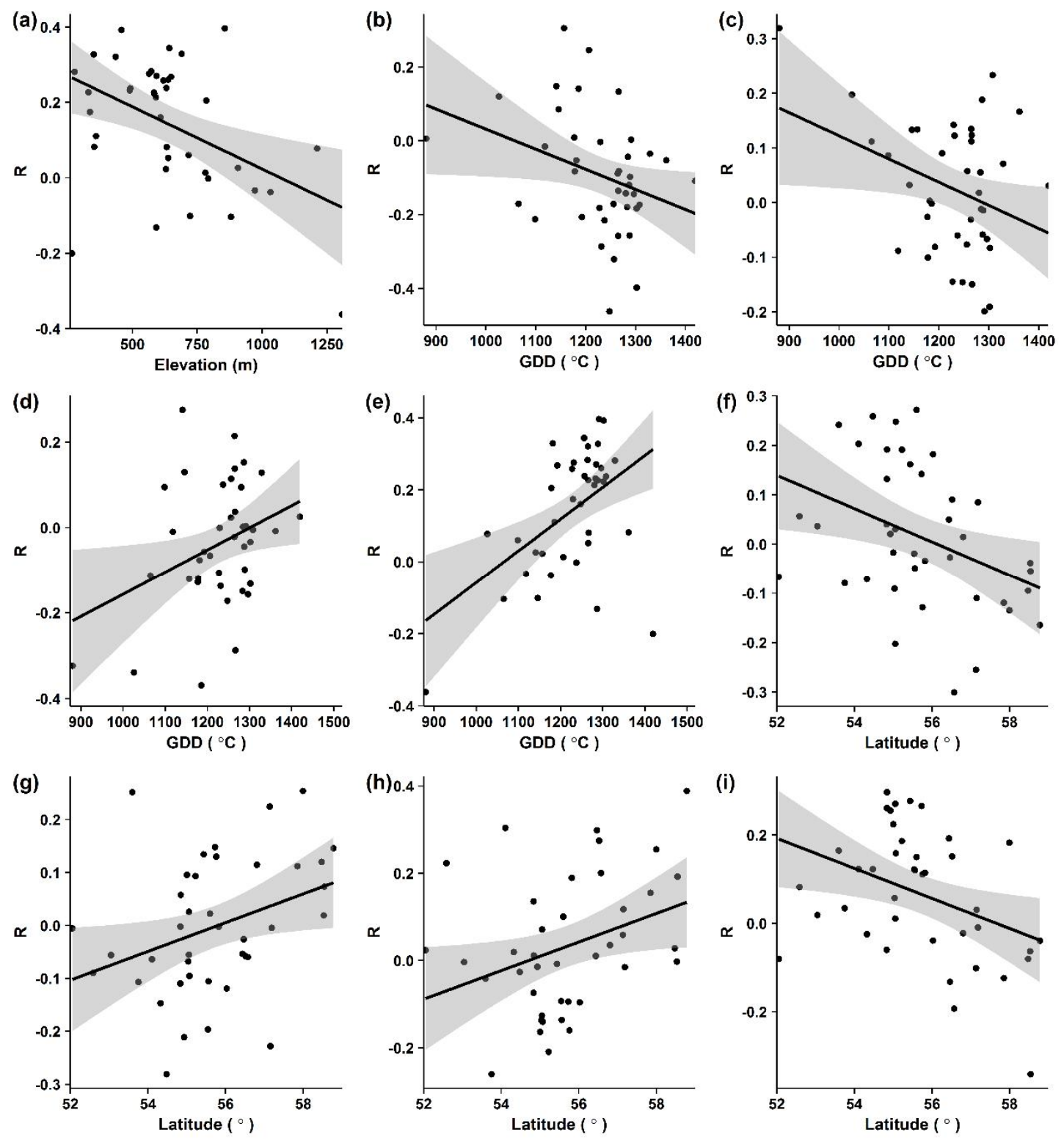

Fig. 5 Variations in the correlations of radial growth and (a) monthly total precipitation of current May with elevation; (b) monthly mean temperature of previous

309 May with growing degree days (GDD $>5^{\circ} \mathrm{C}$ ), (c) monthly mean temperature of current

310 May with growing degree days $\left(\mathrm{GDD}>5^{\circ} \mathrm{C}\right)$, (d) monthly total precipitation of

311 previous October with growing degree days (GDD > $5^{\circ} \mathrm{C}$ ), (e) monthly total 
312 precipitation of current May with growing degree days $\left(\mathrm{GDD}>5^{\circ} \mathrm{C}\right)$; (f) monthly mean

313 temperature of previous June with different latitudes, (g) monthly mean temperature of

314 previous November with different latitudes, (h) monthly total precipitation of previous

315 June with different latitudes, (i) monthly total precipitation of current July with different

316 latitudes. The shaded area presents $95 \%$ confidence intervals.
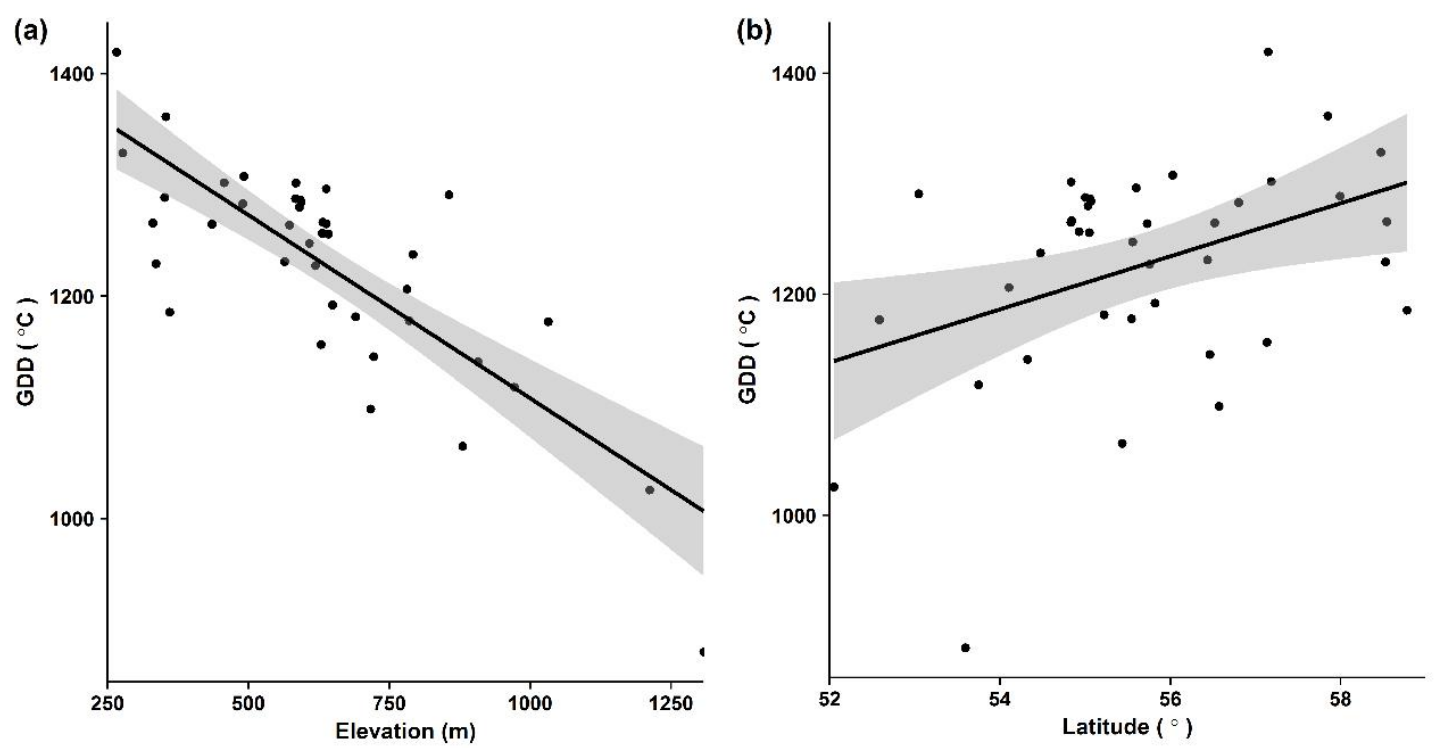

321 Fig. 6 Variation of growing degree days (GDD $>5^{\circ} \mathrm{C}$ ) with (a) elevations, and (b)

322 latitudes. The shaded area presents $95 \%$ confidence intervals.

324 The correlation coefficients of radial growth and monthly total precipitation of current

325 May decreased with increasing elevation (Fig. 5a, $p=0.038$ ). Similarly, correlations of 326 radial growth and monthly mean temperature of previous May (Fig. 5b, $p=0.041$ ) and 327 current May (Fig. 5c, $p=0.034$ ) decreased with increasing GDD. In comparison, 
correlations of radial growth and monthly total precipitation of previous October (Fig. 5d, $p=0.029$ ) and current May (Fig. 5e, $p=0.001$ ) increased with GDD. The correlations of radial growth and monthly mean temperature of previous June (Fig. 5f, $p=0.016$ ), and monthly total precipitation of current July (Fig. 5i, $p=0.016$ ) declined when latitudes increased. In contrast, as latitudes increased, correlations of radial growth and monthly mean temperature of previous November (Fig. $5 \mathrm{~g}, p=0.031$ ), and monthly total precipitation of previous June (Fig. $5 \mathrm{~h}, p=0.031$ ) increased. In the study area, GDD decreased with increasing elevations while it increased with increasing latitudes (Fig. 6). In summary, the correlations of radial growth and temperature decreased with increasing GDD while the correlations of radial growth and precipitation showed an upward trend when the GDD increased (Fig. 5). It suggests that the radial growth of white spruce in northern stands is often more strongly limited by temperature-induced drought due to the higher GDD.

\section{Discussion}

Growth estimates from the nonlinear process-based VS-Lite model indicated that soil moisture often limited the radial growth of white spruce at most sites and temperatureinduced drought was the primary limiting factor for radial growth. In addition, the radial growth of white spruce in northern stands is often more strongly limited by temperatureinduced drought due to the higher temperature and lower precipitation in growing season. As the global climate change is in progress, specific forest management 
strategies that mitigate the potential effects of increased drought stress are needed to

350 maintain these forests.

\subsection{Response of radial growth to climate variables}

353 The correlation analysis indicated that the previous year summer temperature imposed

354 a strong negative impact on the radial growth of white spruce while the precipitation of 355 previous year had significant and positive impacts on the radial growth (Fig. 2). In 356 summer, the high temperature can increase evapotranspiration, resulting in water deficit 357 (D'Arrigo et al., 2004; Huang et al., 2010), which was also confirmed by the results of 358 our VS-Lite model. The impact of previous year temperature was also consistent with 359 the carry-over effect (Cook and Kairiukstis, 1990; Fritts, 2001; Rammig et al., 2015), 360 which refers to the phenomenon that nutrient storage of the previous year also exerts 361 significant effect on the growth of the following year. Likewise, the total 362 photosynthates of previous year could be reduced owing to the temperature-induced 363 drought. As a result, the growth rate of white spruce in the following year declined due 364 to the insufficient carbohydrates stored.

366 In current growing season, radial growth was often positively correlated with 367 precipitation of current May and June while showed a negative response to the 368 temperature (Fig. 3). In a water-deficit environment, sufficient precipitation can 369 promptly alleviate the drought stress and impose a positive effect on radial growth 370 through improving the production of total xylem cell (Deslauriers et al., 2016). 
371 Therefore, the strong positive effect of precipitation on the radial growth was observed 372 in both previous and current growing season. Overall, these results suggest that drought

373 is the primary limiting factor for the growth of white spruce. Prior to the onset of winter

374 freezing, white spruce could perform photosynthesis to store energy and impose a 375 positive effect on the radial growth like other evergreen conifers (Malhi et al., 1999;

376 Miyazawa and Kikuzawa, 2005). As a consequence, the radial growth positively 377 correlated with temperature between October and December of the previous year (Table 378 2, Fig. 2).

\subsection{Assessment of the VS-Lite model}

381 The results of the VS-Lite model indicated that the radial growth in 28 sites were limited 382 by moisture while the temperature limited ones were only found in four sites (Fig. 4). 383 With these results, the VS-Lite model also revealed that temperature-induced drought 384 was the main limiting factor for the radial growth of white spruce. Compared with the 385 empirical linear statistics, the model can directly reflect the impact of soil moisture. For 386 example, the correlation analysis can only reflect the indirect impact of temperature and 387 precipitation on the radial growth, then inferring the temperature-induced drought 388 effect. In addition, the model can describe the monthly variation in the response of 389 radial growth to climate variables through the simulated response curves of $g_{T}$ and $g_{M}$

390 (Fig. 4). In summary, the VS-Lite model can capture the drought signal and simulate 391 the radial growth of white spruce in the boreal forest of Alberta. For example, according 392 to the results of VS-Lite model, there were eight sites where the simulated values of 
$g_{T}$ and $g_{M}$ in summer were similar (Fig. 5). It suggests that the radial growth in these

394 sites was limited neither by temperature nor precipitation, which might be contributed

395 by the site-specific effects (Gewehr et al., 2014). However, 10 out of 40 simulated tree-

396 ring chronologies did not significantly correlate with the actual residual chronologies

397 ( $p>0.05)$. This suggests that improvement is still needed for the VS-Lite model to more

398 accurately simulate the responses of radial growth to climate variables and predict the

399 impact of climate change on forest ecosystems. Other factors such as competition or

400 micro-site conditions (Huang et al., 2013) might play an important role in determining

401 the tree growth at these mid-latitude boreal sites, and have the potential to be included

402 in future versions of the model.

403

404

\subsection{Spatial variations in the growth-climate relationship}

405 Results indicated that the radial growth in northern sites is more likely to suffer from

406 drought stress (Fig. 5). Overall, typical dry continental climate with cold winters and

407 warm summers prevail in the study area (Canada, 2010). During the period between

4081971 and 2000, at the southern part of the study area, the mean annual total precipitation

409 was $535.4 \mathrm{~mm}$ with $30 \%$ in the form of snow and in the northern area, the value was

$410394.1 \mathrm{~mm}(34 \%$ as snow) (Canada, 2010). Therefore, mean annual precipitation in the

411 higher latitudes was ca. $140 \mathrm{~mm}$ less than in lower latitudes, and the percentage of

412 precipitation in the form of snow in higher latitudes exceeds that of in lower latitudes.

413 Consequently, the radial growth of white spruce in northern stands is more strongly

414 limited by temperature-induced drought due to the higher GDD and lower precipitation. 
416 Results showed that the correlations of radial growth and monthly total precipitation in

417 current July decreased with the increasing of latitudes (Fig. 5i), which was opposite to 418 the latitudinal response for the precipitation in previous June (Fig. 5h). In a water-deficit 419 environment, an increment of precipitation can promptly alleviate the drought stress 420 and promote radial growth (Deslauriers et al., 2016). In the study region, the monthly 421 total precipitation and monthly mean temperature often increased from June to July 422 (Appendix S7). However, more precipitation dropped in northern region than the 423 southern region (Appendix S8a). In contrast, less temperature increased in the northern 424 region than the southern region (Appendix S8b). As a result, in July, trees in the south 425 often grow in a hot and dry environment, therefore radial growth being more sensitive 426 and positively responding to the increment of precipitation in the south.

428 In winter, with the increasing of latitudes, correlations of radial growth and temperature 429 of previous November gradually converted from negative to positive (Fig. 5g). The 430 Chinook winds that occurred in southern Alberta can reduce tree growth through 431 drastically raising the winter temperature and contributing to the loss of soil moisture 432 (Lotan and Critchfield, 1990; Nkemdirim, 1996; Chhin et al., 2008). As a consequence, 433 the latitudinal response to the temperature-growth relationship in winter was negative 434 in southern regions. In comparison, at low winter temperature in higher latitudes, due 435 to freezing stress a warmer winter could reduce the damage of tree tissues, such as buds 436 and roots (Miller-Rushing and Primack, 2008). In addition, in early winter with higher 
438 positive effect on the radial growth like other evergreen coniferous species (Malhi et 439 al., 1999; Miyazawa and Kikuzawa, 2005). At last, the initiation of growth could also 440 be delayed for freezing-induced cavitation in cold winter (Wang et al., 1992). Therefore, 441 a warmer early winter is able to facilitate the growth of white spruce in northern area.

\section{Conclusions}

444 Temperature-induced drought was the dominant limiting factor for the radial growth of 445 white spruce, which contributed to the spatial variation in climate-growth relationship 446 as well. The rate of warming in the Canadian boreal forests is predicted to be twice the 447 global average, which will likely lead to severe drought stress in Alberta boreal forests 448 over the next several decades (Price et al., 2013; Wang et al., 2014). To maintain and 449 utilize these forests sustainably, considerable concern on the temperature-induced 450 drought issue is needed in the future forest management. In addition, for the potential 451 nonlinear and unstable response of white spruce to climate variables, process-based 452 forward models in combination with climate predictions from global circulation models 453 have the potential to predict future outcomes from these forests.

\section{Acknowledgements}

456 This project was funded by the 100 Talents Program of the Chinese Academy of 457 Sciences [CAS project number Y421081001]. National Natural Science Foundation of 458 China [NSFC grant numbers 31550110208, 31570584], China Postdoctoral Science 
459 Foundation [grant number 2015M582433], Academy of Finland [projects numbers $4601284701,1282842,285630$ ] and ICOS-Finland [project number 281255]. LC thanks 461 the China Scholarship Council (CSC) for supporting his studies in Japan. Other funding 462 agencies include National Natural Science Foundation of China [grant number 463 31570584], Natural Science and Engineering Research Council of Canada, Mixedwood 464 Management Association, and Forest Resource Improvement Association of Alberta.

\section{References}

Andreu-Hayles, L., D’arrigo, R., Anchukaitis, K.J., Beck, P.S., Frank. D., Goetz, S., 2011. Varying boreal forest response to Arctic environmental change at the Firth River, Alaska. Environ. Res. Lett., 6(4), 045503, doi:10.1088/17489326/6/4/045503.

AESRD, 2012. Phase 3 Forest Inventory. Alberta Environment and Sustainable Resource Development, Available from: http://srd.alberta.ca/ MapsPhotosPublications/Maps/ResourceData Product Catalogue/ ForestVegetationInventories.aspx [Access on July 8, 2013].

Bates, D., Maechler, M., Bolker, B., Walker, S., 2014. LME4: Linear mixed-effects models using Eigen and S4. R package version, 1.

Beckingham, J., Corns, I., Archibald, J., 1996. Field Guide to Ecosites of West-central Alberta. Natural Resources Canada. Canadian Forest Service, northwest Region, northern Forestry Centre Special Report, 9.

Breitenmoser, P., Brönnimann, S., Frank, D., 2014. Forward modelling of tree-ring width and comparison with a global network of tree-ring chronologies. Clim. Past, 10(2), 437-449.

Bunn, A.G., 2008. A dendrochronology program library in R (dplR). Dendrochronologia, 26(2), 115-124.

485 Canada, E., 2010. Canadian Climate Normals or Averages 1971-2000. National 
Climate Data and Information Archive.

487 Chhin, S., Hogg, E.T., Lieffers, V.J. and Huang, S., 2008. Potential effects of climate 488 change on the growth of lodgepole pine across diameter size classes and ecological regions. For. Ecol. Manage., 256(10): 1692-1703.

490 Chavardès, R.D., Daniels, L.D., Waeber, P.O., Innes, J.L., Nitschke, C.R., 2013

491 Unstable climate- growth relations for white spruce in southwest Yukon, Canada.

492 Clim. change, 116(3-4), 593-611.

493 Cook, E.R., Esper, J., D’Arrigo, R.D., 2004. Extra-tropical Northern Hemisphere land 494 temperature variability over the past 1000 years. Quat. Sci. Rev., 23(20), $495 \quad 2063-2074$.

496 Cook, E.R., Kairiukstis, L.A., 1990. Methods of dendrochronology: applications in 497 the environmental sciences, Kluwer, Dordrecht.

498 Cumming, S., Schmiegelow, F., Burton, P., 2000. Gap dynamics in boreal aspen 499 stands: is the forest older than we think? Ecol. Appl., 10(3), 744-759.

500 D'Arrigo, R., Wilson, R. and Jacoby, G., 2006. On the long-term context for late 501

D'Arrigo, R., Wilson, R., Liepert, B., Cherubini, P., 2008. On the 'divergence problem' in northern forests: a review of the tree-ring evidence and possible causes. Global Planet. Change, 60(3), 289-305.

D'arrigo, R.D., Kaufmann, R.K., Davi, N., Jacoby, G.C., Laskowski, C., Myneni,

510 Deslauriers, A., Huang, J.-G., Balducci, L., Beaulieu, M., Rossi, S., 2016. The 511 contribution of carbon and water in modulating wood formation in black spruce saplings. Plant Physiol., 170(4), 2072-2084.

513 Dixon, R.K., Solomon, A., Brown, S., Houghton, R., Trexier, M., Wisniewski, J., 514 1994. Carbon pools and flux of global forest ecosystems. Science, 263, 185-190. 
515 Esper, J., Cook, E.R., Schweingruber, F.H., 2002. Low-frequency signals in long tree-

516 ring chronologies for reconstructing past temperature variability. Science, 517 295(5563), 2250-2253.

518 Esper, J., Frank, D., 2009. Divergence pitfalls in tree-ring research. Clim. Change, 519 94(3), 261-266.

520 Fritts, H., 2001. Tree Rings and Climate. The Blackburn Press, Caldwell.

521 Gewehr, S., Drobyshev, I., Berninger, F. and Bergeron, Y., 2014. Soil characteristics 522 mediate the distribution and response of boreal trees to climatic variability. Can. J. $523 \quad$ For. Res., 44(5): 487-498.

524 Hogg, E., Barr, A., Black, T., 2013. A simple soil moisture index for representing 525 multi-year drought impacts on aspen productivity in the western Canadian 526 interior. Agric. For. Meteorol., 178, 173-182.

527 Hogg, E., Brandt, J., Michaelian, M., 2008. Impacts of a regional drought on the 528 productivity, dieback, and biomass of western Canadian aspen forests. Can. J. 529 For. Res., 38(6), 1373-1384.

530 Hogg, E., Brandt, J.P., Kochtubajda, B., 2005. Factors affecting interannual variation 531 in growth of western Canadian aspen forests during 1951-2000. Can. J. For. Res., 532 $35(3), 610-622$.

533 Hogg, E.H., 1994. Climate and the southern limit of the western Canadian boreal 534 forest. Can. J. For. Res., 24(9), 1835-1845.

535 Hogg, E.H., 1997. Temporal scaling of moisture and the forest-grassland boundary in 536 western Canada. Agric. For. Meteorol., 84(1), 115-122.

537 Holmes, R.L., 1983. Computer-assisted quality control in tree-ring dating and 538 measurement. Tree-Ring Bull., 43, 69-78.

539 Huang, J.-G., Stadt, K.J., Dawson, A., Comeau, P.G., 2013. Modelling growth540 competition relationships in trembling aspen and white spruce mixed boreal 541 forests of Western Canada. PLoS One, 8(10): e77607, 542 doi:10.1371/journal.pone.0077607.

543 Huang, J., Tardif, J.C., Bergeron, Y., Denneler, B., Berninger, F., Girardin, M.P., 2010. 
Radial growth response of four dominant boreal tree species to climate along a latitudinal gradient in the eastern Canadian boreal forest. Glob. Change Biol., 16, $711-731$.

Hughes, M.K., Swetnam, T.W., Diaz, H.F. 2010. Dendroclimatology: progress and prospects, Springer Science \& Business Media.

Hutchinson, M.F., 2004. ANUSPLIN Version 4.3. Center for Resource and Environmental Studies, Australian National University, Available at http://fennerschool.anu.edu.au/publications /software/ anusplin.php [accessed 12 December 2008].

Intergovernmental Panel on Climate Change (IPCC), 2014. 'Agriculture, forestry, and

Jacoby, G.C., D'Arrigo, R.D., 1995. Tree ring width and density evidence of climatic and potential forest change in Alaska. Global Biogeochem. Cycles, 9(2), 227234.

Jones, P.D., Briffa, K.R., Osborn, T.J., Lough, J.M., Van Ommen, T.D., Vinther, B.M., ... \& Xoplaki, E., 2009. High-resolution palaeoclimatology of the last millennium: a review of current status and future prospects. The Holocene, 19(1), $3-49$.

Kasischke, E.S., Stocks, B.J., 2012. Fire, climate change, and carbon cycling in the boreal forest, 138. Springer Science \& Business Media.

Lindahl, B.D., Ihrmark, K., Boberg, J., Trumbore, S.E., Högberg, P., Stenlid, J., Finlay, R.D., 2007. Spatial separation of litter decomposition and mycorrhizal nitrogen uptake in a boreal forest. New Phytol., 173(3), 611-620.

Lotan, J.E. and Critchfield, W.B., 1990. Pinus contorta Dougl. ex. Loud. Silvics of North America, 1: 302-315.

Lloyd, A.H., Bunn, A.G., Berner, L., 2011. A latitudinal gradient in tree growth response to climate warming in the Siberian taiga. Global Change Biol., 17(5), 
574 Lloyd, A.H., Duffy, P.A., Mann, D.H., 2013. Nonlinear responses of white spruce growth to climate variability in interior Alaska. Can. J. For. Res., 43(999), 331-

Lloyd, A.H., Fastie, C.L., 2002. Spatial and temporal variability in the growth and climate response of treeline trees in Alaska. Clim. Change, 52(4), 481-509.

Malhi, Y., Baldocchi, D., Jarvis, P., 1999. The carbon balance of tropical, temperate and boreal forests. Plant Cell Environ., 22(6), 715-740.

Mann, M.E., Bradley, R.S., Hughes, M.K., 2002. Northern Hemisphere temperatures during the past millennium: inferences, uncertainties, and limitations. Geophys.

Mäkinen, H., Nöjd, P., Kahle, H.P., Neumann, U., Tveite, B., Mielikäinen, K., Röhle, H. and Spiecker, H., 2002. Radial growth variation of Norway spruce (Picea abies (L.) Karst.) across latitudinal and altitudinal gradients in central and northern Europe. For. Ecol. Manage., 171(3), 243-259. Res. Lett., 26(6), 759-762.

Ma, Z., Peng, C., Zhu, Q., Chen, H., Yu, G., Li, W., Zhou, X., Wang, W., Zhang, W., 2012. Regional drought-induced reduction in the biomass carbon sink of Canada's boreal forests. Proc. Natl. Acad. Sci. U.S.A., 109(7):2423-2427.

Michaelian, M., Hogg, E.H., Hall, R.J., Arsenault, E., 2011. Massive mortality of aspen following severe drought along the southern edge of the Canadian boreal forest. Global Change Biol., 17(6), 2084-2094.

Miller-Rushing, A.J., Primack, R.B., 2008. Effects of winter temperatures on two birch (Betula) species. Tree Physiol., 28(4), 659-664.

Miyazawa, Y., Kikuzawa, K., 2005. Winter photosynthesis by saplings of evergreen broad-leaved trees in a deciduous temperate forest. New Phytol., 165(3), 857866.

Nkemdirim, L.C., 1996. Canada's chinook belt. Int. J. climatol., 16(4): 441-462.

Peng, C. et al., 2011. A drought-induced pervasive increase in tree mortality across

602 Porter, T.J., Pisaric, M.F., 2011. Temperature-growth divergence in white spruce 
forests of Old Crow Flats, Yukon Territory, and adjacent regions of northwestern North America. Global Change Biol., 17(11), 3418-3430.

Price, D.T., Alfaro, R.I., Brown, K.J., Flannigan, M.D., Fleming, R.A., Hogg, E.H., Girardin, M.P., Lakusta, T., Johnston, M., McKenney, D.W., Pedlar, J.H., 2013. Anticipating the consequences of climate change for Canada's boreal forest ecosystems. Environ. Rev., 21(4), 322-365.

Rammig, A., Wiedermann, M., Donges, J.F., Babst, F., von Bloh, W., Frank, D., Thonicke, K. and Mahecha, M.D., 2015. Coincidences of climate extremes and anomalous vegetation responses: comparing tree ring patterns to simulated productivity. Biogeosciences, 12(2), 373-385.

Speer, J.H., 2010. Fundamentals of tree-ring research, University of Arizona Press.

Stadt, K.J., Huston, C., Coates, K.D., Feng, Z., Dale, M.R., Lieffers, V.J., 2007. Evaluation of competition and light estimation indices for predicting diameter growth in mature boreal mixed forests. Ann. For. Sci., 64(5), 477-490.

Stocks, B.J., Fosberg, M.A., Lynham, T.J., Mearns, L., Wotton, B.M., Yang, Q., Jin, J.Z., Lawrence, K., Hartley, G.R., Mason, J.A. and McKenney, D.W., 1998. Climate change and forest fire potential in Russian and Canadian boreal forests. Clim. Change, 38(1), 1-13.

R Core Team, 2015. R: A language and environment for statistical computing. $\mathrm{R}$ Foundation for Statistical Computing, Vienna, Austria. URL https://www.Rproject.org/.

Tolwinski-Ward, S., Anchukaitis, K.J., Evans, M.N., 2013. Bayesian parameter estimation and interpretation for an intermediate model of tree-ring width. Clim. Past, 9, 1481-1493.

Tolwinski-Ward, S.E., Evans, M.N., Hughes, M.K., Anchukaitis, K.J., 2011. An efficient forward model of the climate controls on interannual variation in treering width. Clim. Dyn., 36(11-12), 2419-2439.

Touchan, R., Shishov, V., Meko, D., Nouiri, I., Grachev, A., 2012. Process based model sheds light on climate sensitivity of Mediterranean tree-ring width. 
Biogeosciences, 9(3), 965-972.

633 Vaganov, E.A., Anchukaitis, K.J., Evans, M.N., 2011. How well understood are the 634 processes that create dendroclimatic records? A mechanistic model of the climatic control on conifer tree-ring growth dynamics. In Dendroclimatology. Springer Science \& Business Media.

Vaganov, E.A., Hughes, M.K., Shashkin, A.V., 2006. Growth dynamics of conifer tree rings: images of past and future environments. Springer Science \& Business Media.

Visser, H., Büntgen, U., D'Arrigo, R., Petersen, A., 2010. Detecting instabilities in tree-ring proxy calibration. Clim. Past, 6(3), 367-377.

Volney, W.J.A., Fleming, R.A., 2000. Climate change and impacts of boreal forest insects. Agric., Ecosyst. Environ., 82(1), 283-294.

Wang, J., Ives, N., Lechowicz, M., 1992. The relation of foliar phenology to xylem embolism in trees. Funct. Ecol., 6(4), 469-475.

Wang, Y., Hogg, E.H., Price, D.T., Edwards, J., Williamson, T., 2014. Past and

Wilmking, M., Juday, G.P., Barber, V.A., Zald, H.S., 2004. Recent climate warming forces contrasting growth responses of white spruce at tree line in Alaska through temperature thresholds. Global Change Biol., 10(10), 1724-1736.

Zhang, Y., Shao, X., Xu, Y., Wilmking, M., 2011. Process-based modeling analyses of 655 Sabina przewalskii growth response to climate factors around the northeastern Qaidam Basin. Chin. Sci. Bull., 56(14), 1518-1525.

Zhang, Y. and Wilmking, M., 2010. Divergent growth responses and increasing temperature limitation of Qinghai spruce growth along an elevation gradient at 
660 Appendix S1. Information of annual total precipitation, minimum temperature $\left(T_{\mathrm{m} \text { in }}\right)$,

661 mean temperature $\left(T_{\text {mean }}\right)$ and maximum temperature ( $\left.T_{\max }\right)$ from 1930 to 2010 for the

66240 white spruce sites along different latitudes.
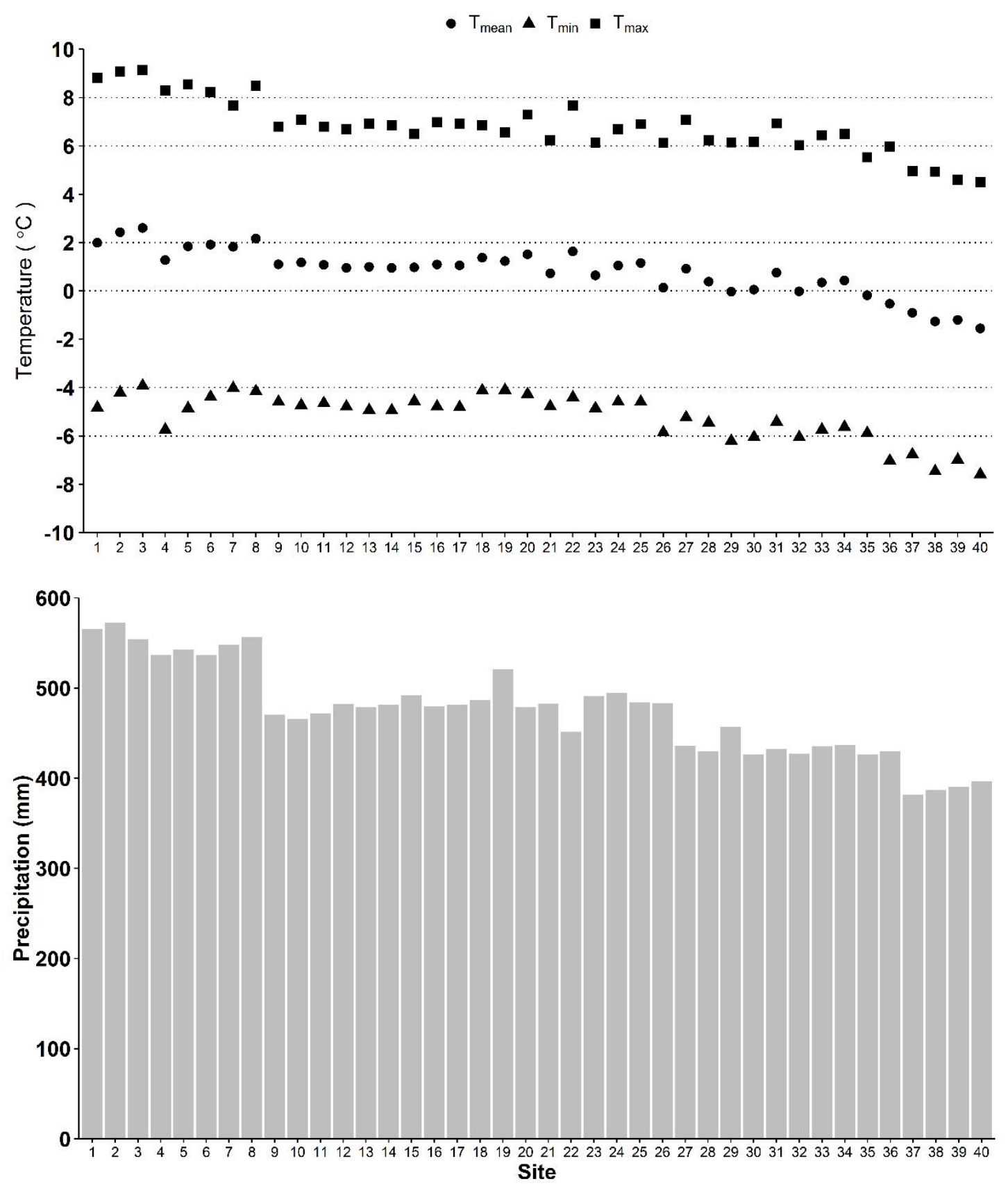
666 Appendix S2. Statistical information of the standard chronologies of white spruce.

\begin{tabular}{|c|c|c|c|c|c|c|c|c|c|c|}
\hline \multirow{2}{*}{ Site } & \multirow{2}{*}{ Latitude } & \multirow{2}{*}{ Longitude } & \multirow{2}{*}{$\begin{array}{l}\text { Elevation } \\
\text { (m) }\end{array}$} & \multirow{2}{*}{ First year } & \multirow{2}{*}{ Last year } & \multirow{2}{*}{$\begin{array}{l}\text { Span } \\
\text { (yrs.) }\end{array}$} & \multicolumn{2}{|c|}{ Tree-ring width $(\mathbf{m m})$} & \multirow{2}{*}{ Skew } & \multirow{2}{*}{ AR1 } \\
\hline & & & & & & & Mean & SD & & \\
\hline S01 & 52.049 & -115.078 & 1212 & 1967 & 2010 & 44 & 1.487 & 0.806 & -0.553 & 0.11 \\
\hline S02 & 52.584 & -115.353 & 1032 & 1975 & 2010 & 36 & 0.794 & 0.364 & -0.73 & -0.084 \\
\hline S03 & 53.045 & -115.014 & 856 & 1964 & 2010 & 47 & 1.330 & 0.936 & 0.261 & 0.503 \\
\hline S04 & 53.595 & -117.669 & 1308 & 1980 & 2007 & 28 & 1.196 & 1.202 & -0.144 & -0.145 \\
\hline S05 & 53.75 & -116.618 & 972 & 1967 & 2010 & 44 & 1.171 & 0.574 & 0.947 & 0.104 \\
\hline S06 & 54.104 & -115.746 & 781 & 1949 & 2010 & 62 & 1.098 & 0.790 & 0.534 & 0.402 \\
\hline S07 & 54.322 & -115.704 & 907 & 1950 & 2010 & 61 & 1.103 & 0.825 & 0.058 & 0.076 \\
\hline S08 & 54.476 & -116.789 & 792 & 1953 & 2010 & 58 & 1.105 & 0.793 & 0.098 & 0.475 \\
\hline S09 & 54.831 & -111.713 & 638 & 1930 & 2010 & 81 & 1.031 & 0.801 & 1.593 & 0.547 \\
\hline $\mathrm{S} 10$ & 54.834 & -111.838 & 584 & 1954 & 2010 & 57 & 1.241 & 0.724 & 0.248 & 0.076 \\
\hline S11 & 54.841 & -111.683 & 632 & 1955 & 2010 & 56 & 1.359 & 0.711 & -0.598 & 0.374 \\
\hline $\mathrm{S} 12$ & 54.929 & -111.543 & 631 & 1955 & 2010 & 56 & 1.281 & 0.763 & -0.276 & 0.157 \\
\hline $\mathrm{S} 13$ & 55.002 & -111.726 & 583 & 1953 & 2010 & 58 & 1.231 & 0.985 & -0.026 & 0.476 \\
\hline S14 & 55.034 & -111.681 & 590 & 1957 & 2010 & 54 & 1.553 & 0.839 & 2.157 & 0.241 \\
\hline S15 & 55.052 & -111.271 & 642 & 1947 & 2010 & 64 & 1.247 & 0.657 & -0.422 & 0.478 \\
\hline S16 & 55.055 & -111.904 & 592 & 1961 & 2010 & 50 & 1.478 & 0.792 & 0.258 & 0.143 \\
\hline S17 & 55.067 & -111.811 & 593 & 1960 & 2010 & 51 & 1.824 & 0.954 & 0.611 & -0.058 \\
\hline S18 & 55.223 & -114.523 & 690 & 1943 & 2010 & 68 & 1.579 & 1.093 & 0.118 & 0.704 \\
\hline S19 & 55.436 & -114.501 & 880 & 1978 & 2010 & 33 & 3.080 & 1.353 & -0.72 & 0.121 \\
\hline $\mathrm{S} 20$ & 55.544 & -118.742 & 785 & 1956 & 2010 & 55 & 1.552 & 0.976 & 1.115 & 0.365 \\
\hline $\mathrm{S} 21$ & 55.558 & -111.237 & 608 & 1954 & 2010 & 57 & 1.777 & 0.961 & -0.5 & 0.183 \\
\hline $\mathrm{S} 22$ & 55.599 & -118.109 & 638 & 1956 & 2010 & 55 & 1.635 & 1.019 & -0.089 & 0.111 \\
\hline $\mathrm{S} 23$ & 55.728 & -110.982 & 573 & 1953 & 2010 & 58 & 0.701 & 0.452 & -0.064 & 0.469 \\
\hline $\mathrm{S} 24$ & 55.757 & -114.177 & 619 & 1953 & 2010 & 58 & 1.349 & 0.908 & 0.304 & 0.482 \\
\hline $\mathrm{S} 25$ & 55.82 & -115.212 & 649 & 1945 & 2010 & 66 & 0.593 & 0.421 & -0.092 & 0.571 \\
\hline $\mathrm{S} 26$ & 56.026 & -110.883 & 492 & 1957 & 2010 & 54 & 1.033 & 0.686 & 0.184 & 0.376 \\
\hline S27 & 56.436 & -115.325 & 564 & 1965 & 2010 & 46 & 0.796 & 0.792 & -0.909 & 0.009 \\
\hline $\mathrm{S} 28$ & 56.465 & -118.313 & 722 & 1968 & 2010 & 43 & 1.170 & 0.954 & -1.1 & 0.284 \\
\hline S29 & 56.519 & -111.298 & 435 & 1967 & 2010 & 44 & 0.955 & 0.544 & -0.322 & 0.27 \\
\hline $\mathrm{S} 30$ & 56.571 & -118.747 & 717 & 1954 & 2010 & 57 & 0.921 & 0.715 & -0.259 & 0.407 \\
\hline S31 & 56.803 & -115.258 & 490 & 1953 & 2010 & 58 & 0.728 & 0.650 & 0.126 & 0.249 \\
\hline S32 & 57.136 & -117.73 & 629 & 1974 & 2010 & 37 & 1.393 & 0.950 & -0.476 & 0.466 \\
\hline S33 & 57.15 & -111.638 & 266 & 1963 & 2010 & 48 & 0.885 & 0.574 & -0.403 & 0.45 \\
\hline S34 & 57.187 & -115.115 & 457 & 1952 & 2010 & 59 & 0.709 & 0.622 & -0.035 & 0.371 \\
\hline S35 & 57.85 & -115.376 & 353 & 1952 & 2010 & 59 & 0.900 & 0.627 & -0.482 & 0.353 \\
\hline S36 & 57.994 & -117.417 & 351 & 1956 & 2010 & 55 & 0.891 & 0.447 & 0.059 & 0.17 \\
\hline S37 & 58.473 & -115.787 & 277 & 1937 & 2010 & 74 & 0.772 & 0.633 & -0.068 & 0.617 \\
\hline S38 & 58.529 & -117.292 & 336 & 1936 & 2010 & 75 & 0.982 & 0.666 & -0.284 & 0.658 \\
\hline S39 & 58.542 & -115.616 & 330 & 1956 & 2010 & 55 & 1.021 & 0.561 & 0.396 & 0.503 \\
\hline S40 & 58.781 & -117.378 & 360 & 1949 & 2010 & 62 & 0.515 & 0.394 & 0.558 & 0.553 \\
\hline
\end{tabular}


667 Appendix S3. Bootstrapped correlation coefficients of radial growth and climate 668 moisture index of (a) previous year and (b) current year. One asterisk and two asterisks 669 represent $p<0.05, p<0.01$, respectively.

670

(a) Climate Moisture Index

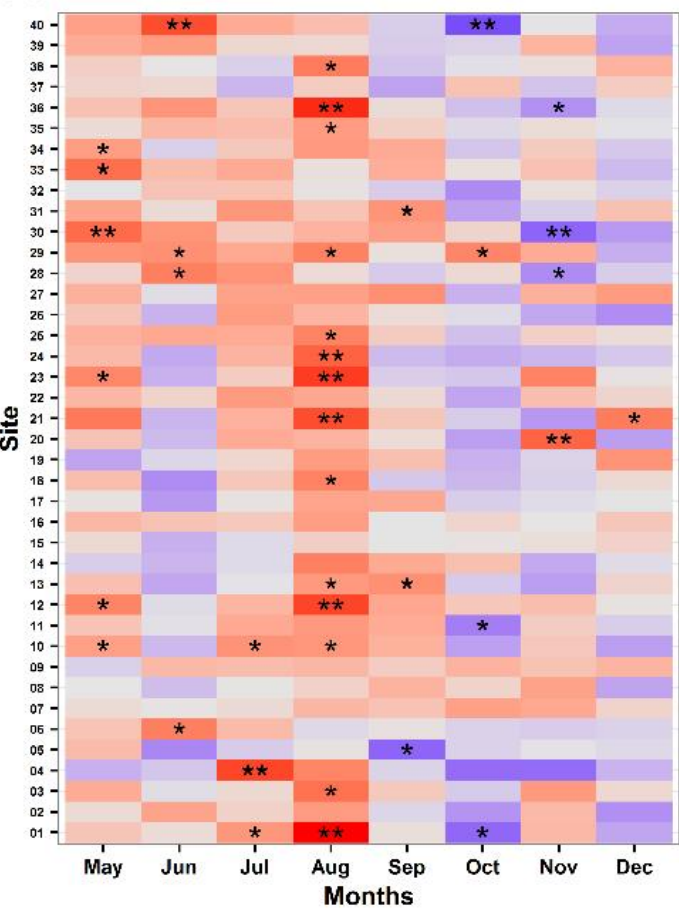

(b) Climate Moisture Index

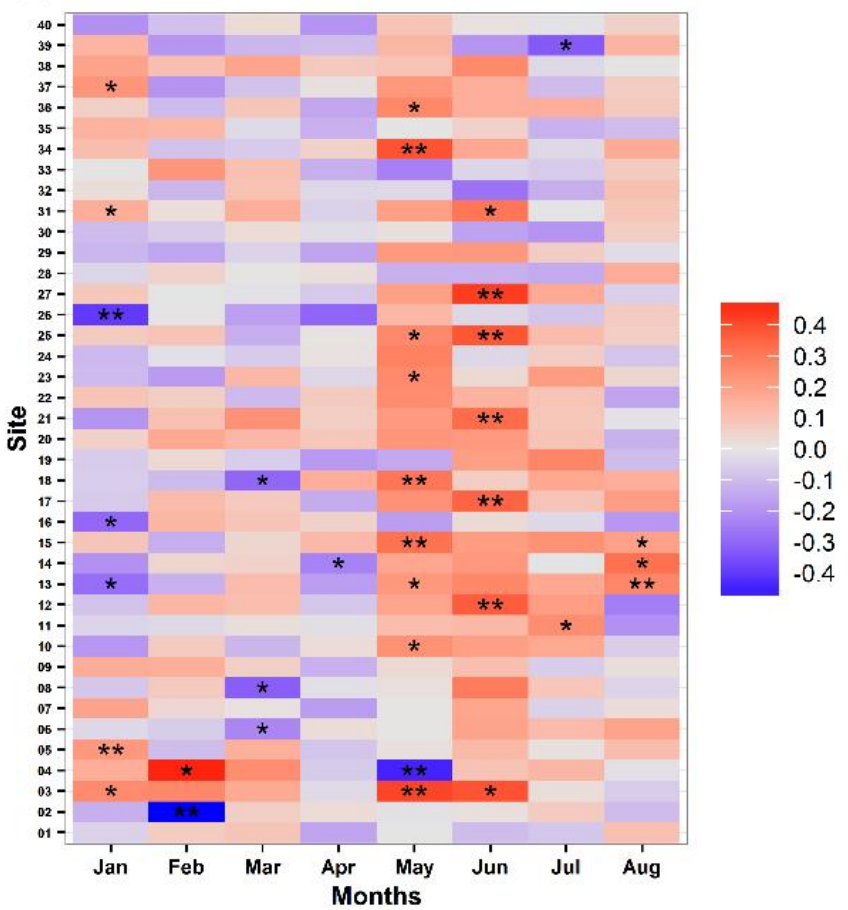


680 Appendix S4. Estimates of the linear mixed models for the effect of climate moisture

681 index (CMI) on the tree-ring width of white spruce. "ns", one asterisk and two asterisks

682 represent $p \geq 0.05, p<0.05$ and $p<0.01$, respectively.

683

\begin{tabular}{crlcccrcrc}
\hline Month & Estimate & \multicolumn{1}{l}{ SE } & $t$ value & Sig. & Month & Estimate & SE & $t$ value & Sig. \\
\hline May & 0.106 & 0.022 & 4.916 & $* *$ & Jan & 0.019 & 0.026 & 0.732 & $\mathrm{~ns}$ \\
June & 0.030 & 0.024 & 1.262 & $\mathrm{~ns}$ & Feb & 0.016 & 0.022 & 0.753 & $\mathrm{~ns}$ \\
July & 0.094 & 0.022 & 4.353 & $* *$ & Mar & 0.013 & 0.022 & 0.612 & $\mathrm{~ns}$ \\
Aug & 0.200 & 0.022 & 9.084 & $* *$ & Apr & -0.040 & 0.022 & -1.835 & $\mathrm{~ns}$ \\
Sep & 0.056 & 0.022 & 2.564 & $*$ & May & 0.126 & 0.025 & 5.008 & $* *$ \\
Oct & -0.048 & 0.023 & -2.04 & $*$ & Jun & 0.147 & 0.023 & 6.326 & $* *$ \\
Nov & 0.025 & 0.024 & 1.043 & ns & Jul & 0.043 & 0.022 & 1.975 & $*$ \\
Dec & -0.001 & 0.022 & -0.041 & ns & Aug & 0.038 & 0.022 & 1.773 & ns \\
\hline
\end{tabular}

684

685

686

687

688

689

690

691

692

693

694

695 
696 Appendix S5. Correlations between the actual and simulated residual chronologies 697 using VS-Lite model. One asterisk and two asterisks represent $p<0.05, p<0.01$, 698 respectively.

699

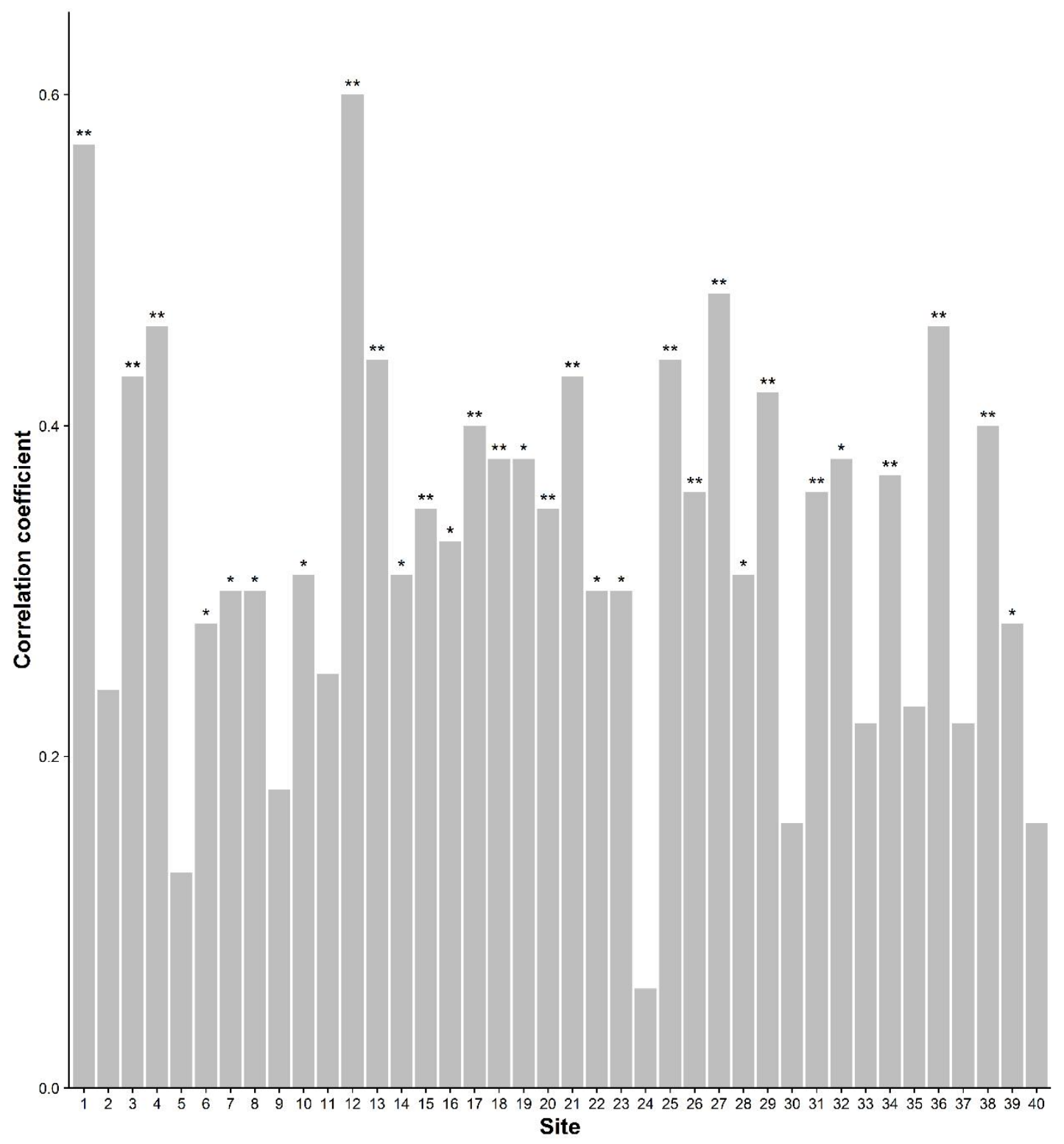



nor soil moisture. The dashed black line and solid grey line represent simulated and between observed and simulated chronologies.

709
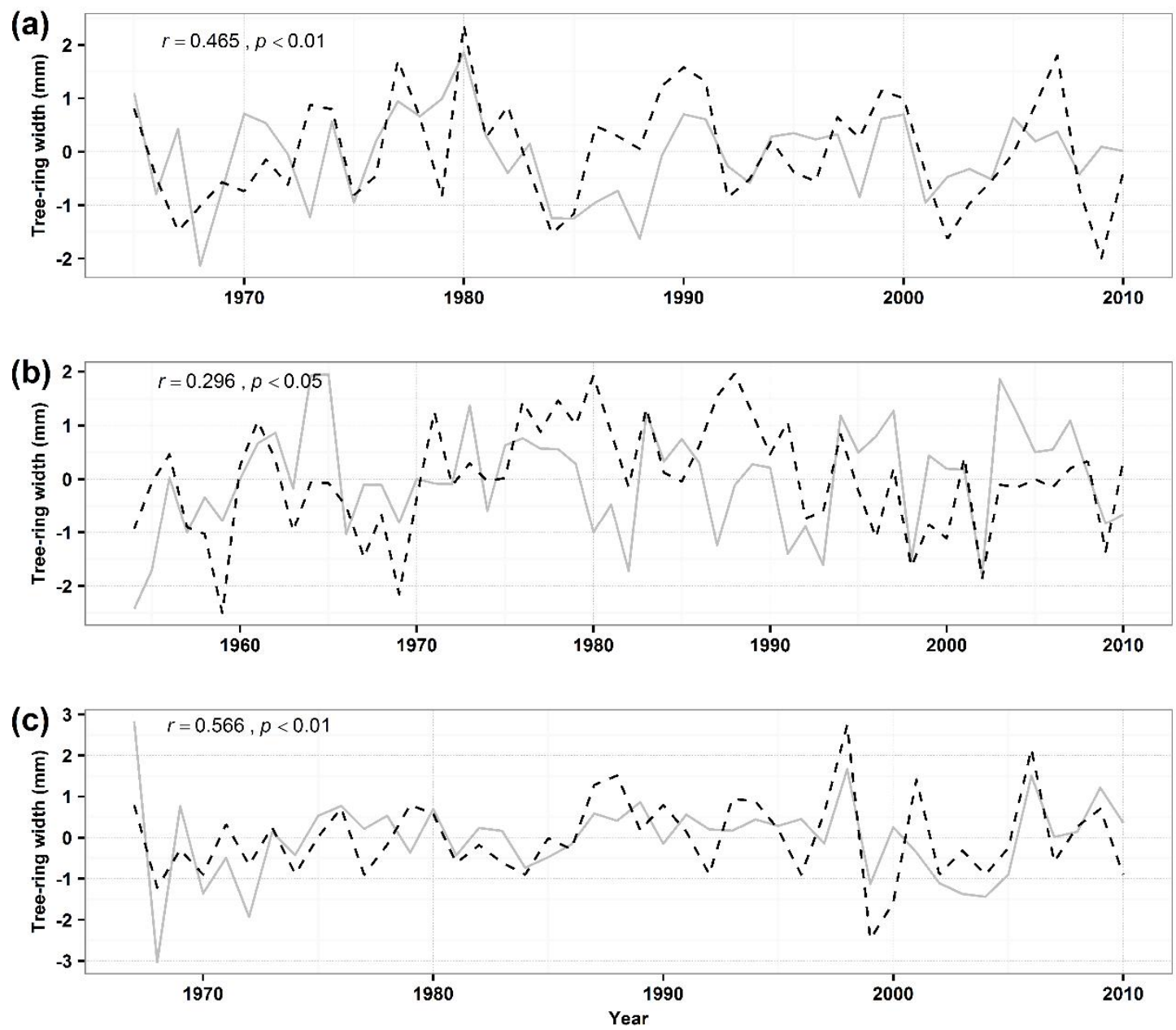
716 Appendix S7. (a) Variation in the monthly total precipitation from 1930 to 2010; (b)

717 variation in the monthly growing degree days $\left(\mathrm{GDD}>5^{\circ} \mathrm{C}\right)$ from 1930 to 2010.

718

719

720

721

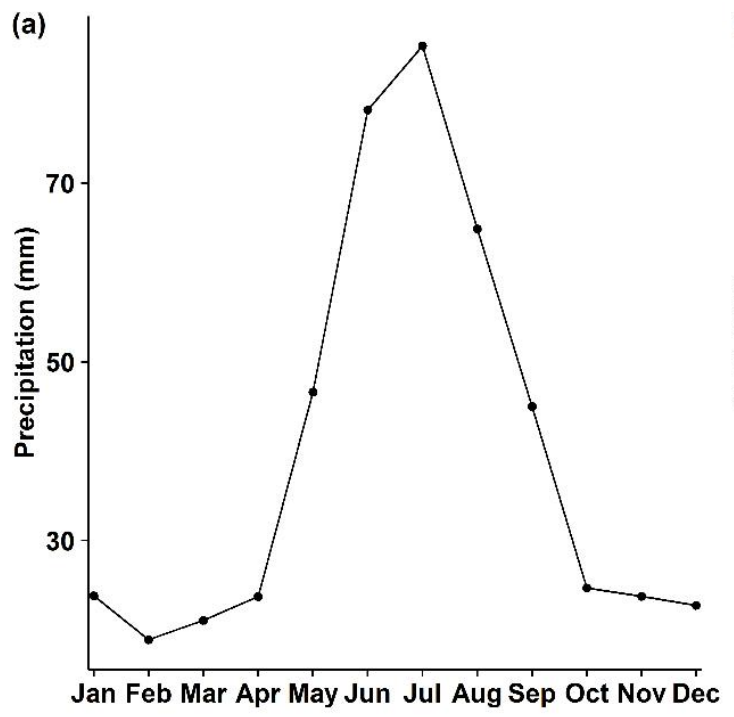

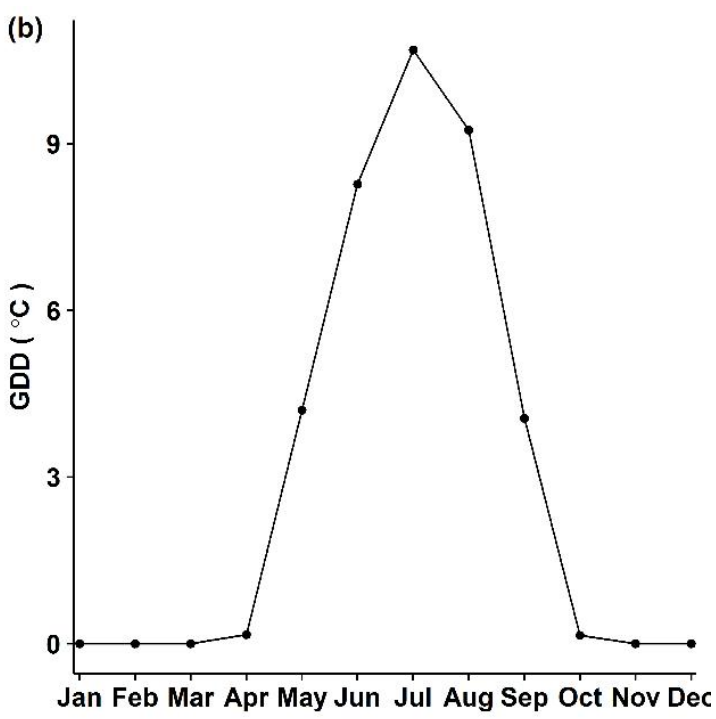


732 Appendix S8. (a) Difference in the monthly total precipitation between June and July

733 along different latitudes; (b) difference in the monthly mean temperature between June

734 and July along different latitudes. The shaded area presents 95\% confidence intervals.

735

736

737
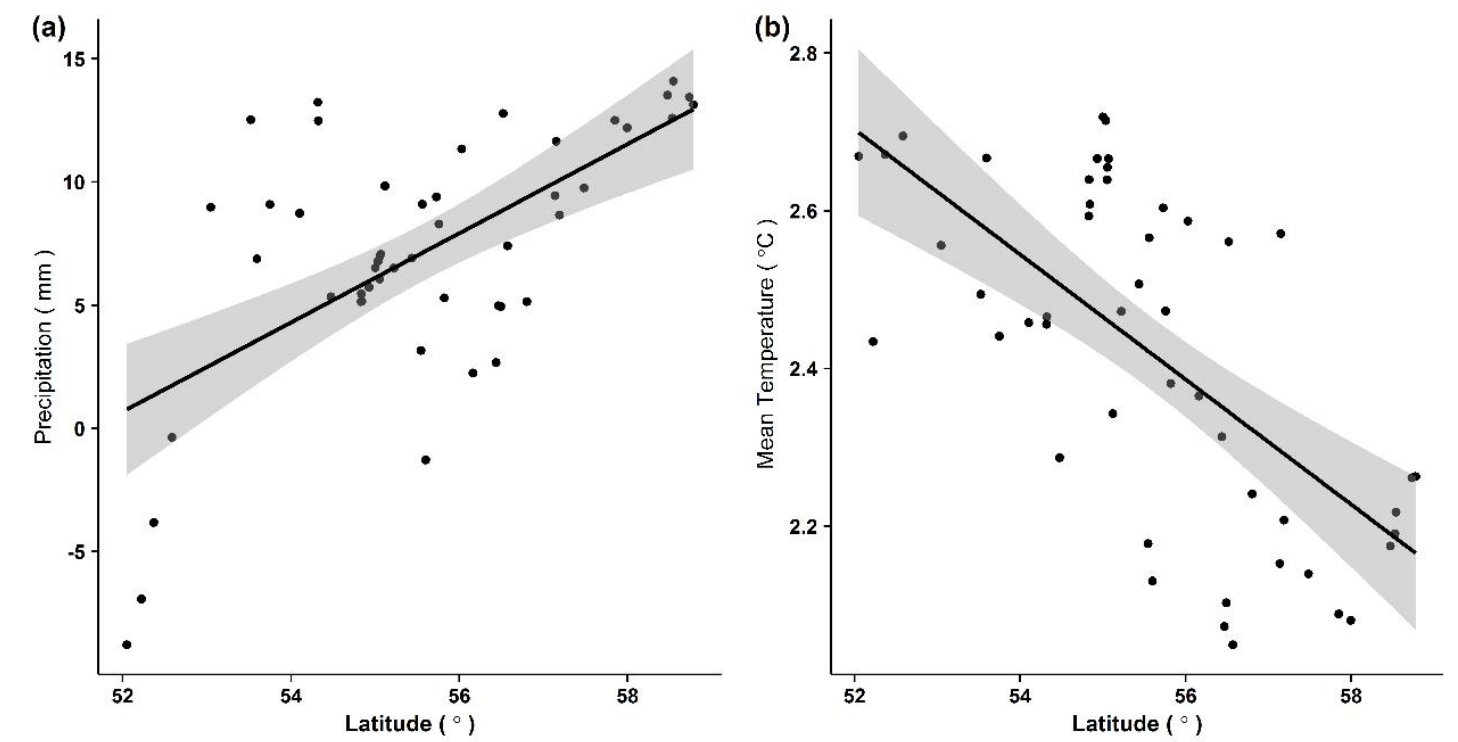

738

739

740

741

742 